\title{
Rapid lipolytic oscillations in ex-vivo adipose tissue explants revealed through microfluidic droplet sampling at high temporal resolution
}

\author{
Juan $\mathrm{Hu}^{1}$, Xiangpeng Li ${ }^{1}$, Robert L. Judd², and Christopher J. Easley ${ }^{1, *}$ \\ ${ }^{1}$ Department of Chemistry and Biochemistry, Auburn University, Auburn, AL 36849, USA \\ ²Department of Anatomy Physiology and Pharmacology, Auburn University, Auburn, AL 36849, USA
}

\begin{abstract}
Our understanding of adipose tissue biology has steadily evolved. While structural and energy storage functionalities have been in the forefront, a key endocrine role for adipocytes was revealed only over the last few decades. In contrast to the wealth of information on dynamic function of other endocrine tissues, few studies have focused on dynamic adipose tissue function or on tool development toward that end. Here, we apply our unique droplet-based microfluidic devices to culture, perfuse, and sample secretions from primary murine epididymal white adipose tissue (eWAT), and from predifferentiated clusters of 3T3L1 adipocytes. Through automated control, oil-segmented aqueous droplets ( 2.6 nL) were sampled from tissue or cells at 3.5-second temporal resolution, with integrated enzyme assays enabling real-time quantification of glycerol (down to $1.9 \mathrm{fmol}_{\text {droplet }^{-1}}$ ). This high resolution revealed previously unreported oscillations in secreted glycerol at frequencies of 0.2 to $2.0 \mathrm{~min}^{-1}(\sim 30-300 \mathrm{~s}$ periods) present in the primary tissue but not in clustered cells. Low-level bursts ( 50 fmol) released in basal conditions were contrasted with larger bursts ( $\sim 300 \mathrm{fmol})$ during stimulation. Further, both fold changes and burst magnitudes were decreased in eWAT of aged and obese mice. These results, combined with immunostaining and photobleaching analyses, suggest that gap-junctional coupling or nerve cell innervation within the intact ex-vivo tissue explants play important roles in this apparent tissue-level, lipolytic synchronization. High-resolution, quantitative sampling by droplet microfluidics thus permitted unique biological information to be observed, giving an analytical framework poised for future studies of dynamic oscillatory function of adipose and other tissues.
\end{abstract}




\section{Introduction}

Dynamic studies of hormone and metabolite secretion from cells and tissues are critical to understand their biochemical and physiological functions and to develop therapeutics for related diseases.

Traditionally, secretion sampling from cells or tissues is done in tubes or well-plates, and the typical temporal resolution is around one to five minutes for metabolites and tens of minutes to hours for hormones, depending on the abundance of targets and restricted by manual handling ${ }^{1-4}$. In tube- or wellbased secretion sampling, a large amount of tissue or cells are required, the temporal resolution is limited, and the sampling from such a static culture system can give results that are significantly different from the true, in vivo response ${ }^{5-8}$. In particular, our understanding of dynamic functionality in adipose tissue is limited, perhaps due to the belated perspective on its endocrine nature as well as the additional culture and sampling challenges caused by adipocyte buoyancy ${ }^{9}$. It is clear that better tools are needed for this purpose, and these tools will require some customized features to deal with adipose tissue.

With a substantial increase in biological applications of microfluidic devices recently, the state-of-the-art in cell culture systems and their temporal limitations have begun to change. Microfluidics has been affirmed as a powerful tool in studies of cell biology such as proliferation, growth, mobility, or response to chemical stimuli ${ }^{10-15}$. One particularly suitable application of microfluidic devices is the investigation of dynamics in ions, genomics, and proteomics in cells or tissues under varying treatments, due to the automatic and precise control of chemical and mechanical microenvironments offered by microfabricated systems, which can better mimic the in vivo situation ${ }^{12,16,17}$. Dynamic changes in metabolites such as glucose, fatty acids, and glycerol are integral to cytokine secretion and cell function in the pancreas, liver, and adipose tissue, yet current techniques remain inadequate to answer questions on short time scales from small amounts of tissue. Needs for improved capabilities, such as on-chip integration of sampling and detection, has led our group and others to develop bioanalytical microfluidic tools for culture or sampling of adipose cells and tissues ${ }^{17-29}$. Continuous-flow systems for high sampling resolution have been developed by Kennedy and co-workers, where integrated enzyme assays quantified secreted glycerol and non-esterized fatty acids from 3T3-L1 adipocytes ${ }^{20,21}$, and by our group from primary adipose tissue using automated microfluidic sampling ${ }^{24}$. To date, however, many dynamic aspects of the 
tissue's function remain a mystery due to a lack of adequate temporal resolution caused by dispersion within mixing channels or static culture conditions. We have recently shown that this problem can be solved using droplet microfluidics with integrated, mix-and-read immunoassays, permitting continuous 15second measurements of insulin secreted by single pancreatic islets ${ }^{25}$. This advancement has set the stage for unique experiments on other tissues, such as adipose tissue, enabled by the high-resolution sampling.

In this work, our aqueous-in-oil droplet sampling device ${ }^{25}$ was further improved to allow an unprecedented 3.5-second temporal resolution, and the introduction of additional assay reagent channels permitted on-chip integrated enzyme reactions for real-time glycerol quantification from cells or tissues. The results revealed previously unreported dynamic behavior in the adipose tissue, which was not present in clustered cell lines. Both peaks and valleys of tissue-secreted glycerol were captured into 2.6 $\mathrm{nL}$ aqueous droplets segmented by an oil phase, allowing unique quantitative burst analyses on wild-type, aged, and obese tissues. As described in detail below, such high resolution results revealed, for the first time, cell-to-cell communication in adipose tissue that is similar to that of pancreatic endocrine tissue.

\section{Results and Discussion}

Microchip Design and Function. Adipose tissue is a critical organ for energy homeostasis by regulating glucose and fat metabolism, and it is also an endocrine organ 9,30. A variety of small molecules are taken up by and released from adipocytes tissue under the regulation of several hormones ${ }^{31}$, and it is important to quantify the uptake and secretion dynamics of these molecules to improve our understanding of the physiological and pathological functions of the tissue. A number of enzymatic assays for small molecules are well-developed, e.g. assays for glucose, glycerol, and non-esterized fatty acids. This improved microfluidic droplet system was designed for sampling into segmented aqueous droplets, reaction of the secretome with enzymatic assay reagents, on-chip incubation, and on-chip readout at higher temporal resolution. The modified droplet-based microfluidic device includes three input channels for substrate, enzyme, and secretion sampling; a T-junction for droplet formation with another inlet for perfluorinated oil as the continuous phase; a reference inlet to introduce our lock-in methodology for high sensitivity 
quantification ${ }^{32,33}$; and a long incubation channel for the reaction of assay reagents with analytes (Fig. 1 and Fig. S-1A). To improve temporal resolution beyond the 15 seconds achieved previously ${ }^{25}$, a serpentine-shaped microvalve with five crossing points was exploited in this device to enhance contact area, effectively increasing oil pumping volume by 8 -fold for each pump cycle, giving a volumetric rate of 9.3 $\mu \mathrm{L} \mathrm{h}^{-1}$ (Fig. S-4). This new design could generate droplets faster and achieve higher temporal resolution, as low as $\sim 3.5$ seconds.

Since adipocytes are buoyant, another important component of the chip is the cell-culture reservoir (Fig. S-1E), fabricated by 3D-printed templating ${ }^{18,25}$. As the schematic in Fig. S-1C demonstrates, the treatment solution was continuously flowing through the tissue, carrying all secreted analytes into the microchannel to be trapped into droplets thereafter. The continuous flow brings fresh media to tissue or cells and takes metabolic molecules away, reducing auto-inhibition of biochemical reactions in the cellarguably more akin to the in vivo situation. We previously showed this sampling design capable of complete capture of analytes from pancreatic islet tissue with high temporal resolution ${ }^{25}$. The flow rate of

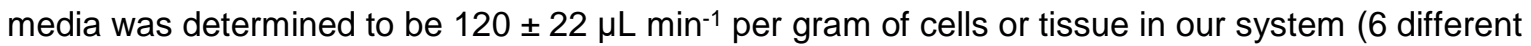
explants), which was designed to be similar to the experimental measurement of blood flow rate through epididymal adipose tissue in the morning, $100 \pm 10 \mu \mathrm{L} \mathrm{min}^{-1}$ per gram tissue in un-anesthetized rats ${ }^{34}$. From the secretion plots below and from calculated flow rates in our previous tests ${ }^{25}$, we concluded that this sampling flow rate was appropriate to carry away secreted analytes without accumulation in the reservoir. This represents a major difference between our continuous flow sampling system and more standard, static sampling methods in tubes or well-plates.

Real-time Quantification of Glycerol Release from 3T3-L1 Adipocytes. Differentiated from 3T3-L1 fibroblasts, 3T3-L1 adipocytes are typically characterized as white adipocytes in their basal bioenergetics and gene expression profile, and they respond sensitively to catecholamines and insulin; the cells are widely used as an in vitro model of white adipocytes ${ }^{35}$. To validate that secreted analytes could be quantified in real time via the microfluidic droplet system, glycerol secretion from 3D spheroids of these cells ( 200 $\mu$ m diameter; Fig. S-9 and supplementary video 2) was quantified under different treatments. 
In Fig. 2A, the lipid droplets in the cells were stained by LipidTox Green to visualize trapped adipocytes and confirm their presence in agarose spheroids. While changing the treatment from high glucose with high insulin (HGHI) to low glucose with low insulin and $20 \mu \mathrm{M}$ isoproterenol (LGLIS), the glycerol released from these adipocyte spheroids was sampled using our microfluidic device, combined with enzyme assay reagents into segmented droplets, then detected by fluorescence imaging in the downstream channel. Isoproterenol, a beta adrenergic agonist, is known to help mimic fasting by stimulating triglyceride breakdown (lipolysis) and release of free fatty acids and glycerol. The processed and calibrated data from 3 representative cell spheroids is shown in Fig. 2A. Glycerol release from the spheroids was observed to increase almost immediately after stimulation, and the secreted amount was increased by 2.5- to 5.5-fold compared to baseline, depending on the cell numbers in the gel droplets. Previous results from others using continuous flowing microfluidics have reported similar fold changes ${ }^{36}$. Also noteworthy is the relatively constant secretion rate that was observed both before and after stimulation, an important point for comparison to tissue results below. Thus, our high-resolution microfluidic droplet sampling system with an integrated enzyme assay was proven functional for assaying cellular secretions and was capable of studying the rapid response of cells to stimuli.

Real-time Quantification of Glycerol Release from eWAT. Primary cells are considered as ideal models for drug discovery and toxicity tests because they are representative of phenotypic gene expression and behavior of organs ${ }^{37}$, as they have undergone development and maturation throughout the life of the animal. However, even short periods of culturing can reduce their specificities if the cells are isolated from the surrounding tissue by digestion. Therefore, when available, undigested primary tissue explants should provide better in vitro models and should present more organotypic secretomes. For this reason, we have used our device to sample glycerol secretion ex vivo from primary murine eWAT explants. At appropriate sizes ( 0.12 $\pm 0.02 \mu \mathrm{L}$ explant volumes) for scaling with the chip operation, eWAT explants were loaded into the cell culture reservoir, and glycerol secretion under different treatments was sampled into droplets and quantified. As shown in Fig. 2B, fast and dramatic changes were observed within one minute after changing the treatment from HGHI to LGLIS, and obvious dynamic changes were superimposed upon these responses. Note that these fast changes would not have been 
observable with other analytical systems, which would have under-sampled the rapid bursts and given a smoothed trace. It is by droplet-based segmentation at our unprecedented 3.5-second temporal resolution that these observations were possible. Surprisingly, glycerol release from eWAT explants exhibited a unique oscillatory pattern (Fig. 2B), a pattern that was not observed in encapsulated 3T3-L1 adipocytes (Fig. 2A). Multiple explants from two 12-week old wild-type mice were tested, and the three representative experiments shown in Fig. 2B exhibited similar oscillations with periods of $\sim 30$ to $300 \mathrm{~s}$ (frequency range of $\sim 0.2$ to $2.0 \mathrm{~min}^{-1}$ ). A few experiments showed some heterogeneity between mice with somewhat different oscillation patterns (see Fig. 6A). These data show that our high-resolution microfluidic sampling system was capable of observing unique function in adipose tissue.

Additional observations were made by sampling at high resolution from explants of aged (20 weeks) or diet-induced obese (DIO) mice (Fig. 2C-D), where a reduced level of oscillatory function was observed in both cases. Also, by comparing pre- and post-treatment levels (Fig. 2E), we observed that the overall average increase in secreted glycerol from adipose tissue explants (12-week WT) was similar to the response from 3T3-L1 adipocytes used in the sixth day after differentiation, with both increasing 3- to 5fold after treatments. These data suggested that the tissue and encapsulated cells were functioning as expected in the microfluidic devices. Conversely, aged ( 20 weeks) and obese (DIO) mice showed decreased fold-changes, perhaps related to decreased connectivity as discussed below.

Unique, Technology-Enabled Data Analyses. Since our micro-analytical system sampled at such high temporal resolution, it was possible to delve deeper into the analysis and carry out fast Fourier transforms (FFTs) on the data. Fig. 3 and Fig. S-10 show the comparisons of oscillatory patterns between encapsulated cell lines and eWAT explants. A windowed, sliding FFT method (128-point moving window, $7.42 \mathrm{~min}$ ) was applied to give the time-dependent spectrograms of glycerol secretion shown in Fig. 3. Even with glycerol secretion intensities represented on a logarithmic scale, mere hints of lower frequency oscillations were observed from cell spheroids (left data), and treatment-dependent changes were not observed. These spectrograms were relatively flat and featureless, akin to those of the cell-free standard curve (not shown). By contrast, rich patterns of oscillatory glycerol secretion were observed in the 
frequency domain data from eWAT tissue explants (right data). All eWAT explants showed strong oscillatory function at frequencies in the range of $\sim 0.2$ and $1.2 \mathrm{~min}^{-1}$ ( $\sim 50$ to $300 \mathrm{~s}$ periods), with an additional group of fast oscillations at $\sim 2 \mathrm{~min}^{-1}$ ( $\sim 30$ second period). Another important observation is that the oscillations were at lower intensities under HGHI treatment, then they were quickly amplified by the LGLIS treatment. In other words, basal oscillations were present at low levels and were simply potentiated by the treatment, which is a unique observation in adipose tissue enabled by our methodology.

Using a more simplified visualization, a low-pass filter with $1.0 \mathrm{~min}^{-1}$ cutoff was applied to the timedomain data (from Fig. 2), standard FFT analysis was carried out, and frequency domain data from 0 to 2 min $^{-1}$ was plotted (Fig. S-10 A-H). Again, little to no glycerol secretion oscillations were observed from the cell spheroids, while strong oscillations were released by the tissue from 12-week-old mice. Interestingly, eWAT tissue from older mice ( 20 weeks) seemed to have lost much of its oscillatory magnitude. Using a similar analysis, Fig. S-10I further demonstrates the differences of average magnitudes in the frequency domain among the tissues, cells, and standard curve. These data further confirmed that oscillations were arising from the tissue, not from the sampling and detection system.

High-resolution microfluidic data also permitted us to investigate glycerol secretion dynamics by individually analyzing bursts of secreted analyte. These burst analysis results are shown in Fig. 4A-E, where each burst of glycerol was treated akin to a peak in chromatographic data. In Fig. 4A, the peak heights of the oscillatory bursts, representing the maximum amount of glycerol in each pulse under different treatments, were calculated and plotted against the peak widths (i.e. full width at half maximum, FWHM). Significant increases in glycerol burst amounts were observed in pulses from eWAT tissues treated by LGLIS compared to HGHI treatment, which contrasts with the unchanged peak heights of pulses from 3T3-L1 cells. This phenotypic difference is further confirmed in Fig. 4B, where accumulated amounts of glycerol in each pulse increased significantly in LGLIS treatments compared to HGHI. Further, as confirmed by the histogram analyses in Fig. 4C and 4D, the observed change in glycerol pulse amount was apparently due to height changes in the bursts, not from the change of peak widths (oscillation periods). This result is in agreement with the interpretation of the time-dependent spectrogram shown in Fig. 3. In Fig. 4E, example calculations of burst amounts are given and shown at higher magnification. 
As mentioned briefly above, another observation was that the fold-increases in glycerol release in response to LGLIS became lower, and the oscillations got smaller and less pronounced in aged or obese mice (Fig. 2C, 2D, 2E, and Fig. S-10G-H). The lack of a difference in glycerol release from eWAT of the 20-week wild-type mouse and DIO mouse may have resulted from the mouse becoming more overweight at 20 weeks compared to 12 weeks, with or without high-fat feeding. This assertion is supported by simply comparing total weights of eWAT extracted from the different types of mice (Fig. S-11). For C57BL/6J mice, eWAT weight is positively correlated with age, linking the issue to obesity. Interestingly, several reports ${ }^{38-43}$ have mentioned that the reduction of glycerol release in obese mice and humans could be a result of decreased expression of the aquaporin 7 (AQP7) gene (Aqp7); indeed, this gene was expressed more in our 9-week-old mice than in the 20 -week-old mice (Fig. S-12). AQP7 is the main transporter of glycerol, and a knockout of Aqp7 results in lowering of plasma glycerol and the diminished response of glycerol secretion to the stimulation of $\beta$-adrenergic signaling. It is therefore possible that AQP7 plays an important role in the dynamic observations shown in this work. However, further investigations are needed to improve our understanding of the mechanisms of glycerol transport and/or intercellular communication and the observed changes related to age and obesity.

Tissue connectivity studies in eWAT. Since we did not observe oscillations from cell spheroids, we hypothesized that our observed glycerol secretion oscillations from eWAT tissue explants were dependent upon cell-to-cell communication within the tissue, such as gap-junctional coupling, aquaporinmediated transport, or other means of connectivity. Gap junctions are channels on cell membranes that permit intercellular communication by facilitating exchange of ions and secondary signaling molecules, as well as other small molecules. Such gap junctional tissue coupling can transfer signals between cells and induce synchronization of electrical and metabolic activities in connective tissue ${ }^{44}$. Notably, synchronization and oscillation of insulin secretion from pancreatic islets have been shown to result from gap junctional electrical coupling of beta-cells, which couples oscillations of $\mathrm{Ca}^{2+}$ that are followed by downstream insulin oscillations ${ }^{45-47}$. Several previous reports have shown that similar gap junctions also exist in adipose tissue ${ }^{48,49}$, although much less work has been done in this area. Adipose tissue is a 
complex organ including multiple cell types, connective tissues, blood vessels, and neuron terminals, thus neuron cell innervation may also provide a means of connectivity in intact adipose tissue ${ }^{50-54}$.

To evaluate if gap junctions and neuron innervation were present in our eWAT explants, immunostaining was first applied to test for the existence of gap junction alpha-1 protein (GJA1, or connexin 43) and tyrosine hydroxylase (TH, marker of sympathetic neuron terminal); results in Fig. 5C-D show these proteins are present. For further evaluation, a Connexin 43 inhibitor (2-aminoethoxydiphenyl borate, 2-APB) and a neurotoxic compound (6-Hydroxydopamine, 6-OHDA) were applied to eWAT explants. These experiments leveraged confocal fluorescence recovery after photobleaching (FRAP) studies with CFDA-AM (5-Carboxyfluorescein diacetate, acetoxymethyl ester) as the cytoplasm-staining dye. CFDA-AM was hydrolyzed to carboxyfluorescein after entering the cells, trapping it within the cells unless it can cross gap junctions, e.g. into a recently photobleached cell, to recover the fluorescence ${ }^{44}$. Using multiple eWAT explants from two different mice, FRAP results showed that the fluorescence recovery rate (ratio between the post-bleach and pre-bleach intensities) reduced when tissues were pretreated with 2-APB, and a further decrease was observed after treatment with 2-APB plus 6-OHDA (Fig. 5A-B). These results suggest that the gap junction inhibitor and the neurotoxic drug both blocked cell-tocell communication throughout the eWAT tissue.

Data in Fig. 6A, collected on our microdevices, further demonstrates the significant reduction or perhaps complete loss of the catecholaminergic effect in lipid metabolism when gap junctions were blocked by the inhibitor 2-APB. Glycerol release did not increase under LGLIS treatment after the tissue was administrated with 2-APB with the HGHI treatment. Similar results were shown in the experiments where tissue was pretreated by 6 -OHDA. When tissues were pretreated with $1.82 \mu \mathrm{g} / \mu \mathrm{L} 6-\mathrm{OHDA}$ in culture media for $8 \mathrm{~h}$, the fold change of glycerol release stimulated by LGLIS +2 -APB was negligible at $0.99 \pm 0.04$ compared to HGHI treatment. Thus, blocking cell-to-cell communication in tissue by pretreating it with either 2-APB or 2-APB +6-OHDA can terminate the catecholaminergic effect directly. Finally, to investigate the more delicate oscillatory patterns in glycerol secretion under the stimulatory condition, an eWAT explant was pre-treated in HGHI, stimulated by LGLIS, then treated with 2-APB while sampling by our microfluidic device. As shown by the spectrogram in Fig. 6B, while oscillations were clearly observed to increase upon stimulation, a loss of oscillatory magnitude was observed after adding 
$100 \mu \mathrm{M}$ of 2-APB. Interestingly, the highest frequency oscillations appeared to undergo the most attenuation, while the lower frequency oscillations were less reduced.

Overall, these results suggest that gap-junctional coupling and nerve cell innervation may play significant roles in the tissue-level, coordinated oscillations observed by our novel microfluidic system. The fact that 3T3-L1 adipocytes did not go through development and were not cultured under conditions to promote gap-junctional connectivity may help explain the observed oscillation deficiency in the clustered cell lines. While further biological studies are warranted to understand the roles that these treatments and others play, as well as the complex burst frequency dependences, our device has been proven herein as a suitable tool for dynamic secretion studies of adipose tissue.

\section{Conclusions}

Our automated microfluidic system ${ }^{25}$ was redesigned and improved to allow on-chip coupled enzyme assays and higher temporal resolution of droplet-based sampling from cells or tissue. Droplets with highly consistent volume were generated without connecting to macroscopic plumbing or perfusion systems. A variety of homogeneous immunoassays and other coupled enzyme assays could be applied in this system in the future to enable unique dynamic studies of small molecules and low-abundance proteins secreted from tissues or cell spheroids. Furthermore, only a few cells or tiny sections of primary tissues are needed for investigation, and different treatment solutions are easily changed and delivered in an automated fashion. Importantly, the segmentation of secretomes into aqueous-in-oil droplets very near the tissue (or cells) was shown to conserve temporal resolution by preventing downstream diffusion and dispersion, and it should be possible to achieve even higher temporal resolution that the $\sim 3.5 \mathrm{~s}$ shown here using clever modifications of the fluidics.

With this high-resolution sampling, investigations of the dynamic secretion patterns of primary adipose tissue explants were achieved quantitatively, and unique glycerol secretion patterns from eWAT tissue were observed for the first time, showing stimulation-dependent oscillatory bursts of glycerol in amounts ranging from $\sim 0.05-1.0 \mathrm{pmol}$ and at periods from $\sim 30-300 \mathrm{~s}$. These patterns were obviously distinct from temporal patterns from encapsulated cell lines, suggesting that cell-to-cell communication in adipose 
tissue plays a role. Other studies (using lower-resolution sampling) have reported plasma glycerol and free fatty acid concentrations to oscillate by regulation of adrenergic signaling at a period of $6 \pm 1 \min 55$, and one group suggested that lipolytic oscillations with 5-min pulses were driven by glycolysis in adipocytes and might have impact on the delivery of FFA and glycerol to the liver ${ }^{3}$. In our investigations, we note that whole adipose tissue explants were analyzed, which can conserve phenotypic characteristics and the local microenvironments within the tissue, compared to isolated adipocytes.

A unique finding in this work was the presence of basal oscillations or bursts in the eWAT tissue even in the absence of stimulation, which appeared to be potentiated or amplified by the treatments. This oscillatory function points to an underlying mode of signal transduction and a possible entrainment mechanism to communicate with other cells and tissues ${ }^{14,56}$. Additional observations showed that age and obesity played a role in diminishing magnitudes of glycerol fold-changes and oscillatory bursts, and we hypothesize that these effects are related to a decline in tissue connectivity. Of course, further studies are needed to detail mechanistic connections among gap junctional coupling, nerve cell innervation, and oscillatory glycerol secretion in adipose tissue. Nonetheless, our results provide evidence that cell-to-cell communication plays a role in lipolytic synchronization and that oscillations exist naturally in the adipose tissue. To our knowledge, these results are the first to show such oscillations in eWAT, and the collection of these data was uniquely enabled by our novel, droplet-based microfluidic sampling and analysis system.

\section{Acknowledgements}

Funding for this work was provided generously by the National Institutes of Health, award R01 DK093810.

\section{Author contributions}

$\mathrm{JH}$ and CJE conceived the experiments and conducted data analyses presented here. XL was involved in modifying the design of the microfluidic system. JH performed the microfluidic chip fabrication, mouse 
tissue extractions, and secretion tests. All authors $(\mathrm{JH}, \mathrm{XL}, \mathrm{RLJ}$, and CJE) participated in data interpretation and writing of the manuscript.

\section{Competing interests}

The authors have no competing interests to declare.

\section{References}

(1) Alarcon, C.; Boland, B. B.; Uchizono, Y.; Moore, P. C.; Peterson, B.; Rajan, S.; Rhodes, O. S.; Noske, A. B.; Haataja, L.; Arvan, P.et al. Pancreatic beta-Cell Adaptive Plasticity in Obesity Increases Insulin Production but Adversely Affects Secretory Function. Diabetes 2016, 65 (2), 438.

(2) El Hachmane, M. F.; Komai, A. M.; Olofsson, C. S. Cooling reduces cAMP-stimulated exocytosis and adiponectin secretion at a Ca2+-dependent step in 3T3-L1 adipocytes. PLoS One 2015, 10 (3), e0119530.

(3) Getty-Kaushik, L.; Richard, A. M.; Corkey, B. E. Glucose-dependent insulin modulation of oscillatory lipolysis in perifused rat adipocytes. Obesity research 2005, 13 (12), 2058.

(4) Wang, Y.; Ali, Y.; Lim, C. Y.; Hong, W.; Pang, Z. P.; Han, W. Insulin-stimulated leptin secretion requires calcium and PI3K/Akt activation. Biochem J 2014, 458 (3), 491.

(5) Guan, A.; Hamilton, P.; Wang, Y.; Gorbet, M.; Li, Z.; Phillips, K. S. Medical devices on chips. Nature Biomedical Engineering 2017, 1, 0045.

(6) Kuo, C. T.; Thompson, A. M.; Gallina, M. E.; Ye, F.; Johnson, E. S.; Sun, W.; Zhao, M.; Yu, J.; Wu, I. C.; Fujimoto, B.et al. Optical painting and fluorescence activated sorting of single adherent cells labelled with photoswitchable Pdots. Nat Commun 2016, 7, 11468.

(7) Sackmann, E. K.; Fulton, A. L.; Beebe, D. J. The present and future role of microfluidics in biomedical research. Nature 2014, 507 (7491), 181.

(8) Toh, Y. C.; Zhang, C.; Zhang, J.; Khong, Y. M.; Chang, S.; Samper, V. D.; van Noort, D.; Hutmacher, D. W.; Yu, H. A novel 3D mammalian cell perfusion-culture system in microfluidic channels. Lab Chip 2007, 7 (3), 302.

(9) Li, X.; Easley, C. J. Microfluidic systems for studying dynamic function of adipocytes and adipose tissue. Anal Bioanal Chem 2018, 410 (3), 791.

(10) Duncombe, T. A.; Tentori, A. M.; Herr, A. E. Microfluidics: reframing biological enquiry. Nat Rev Mol Cell Biol 2015, 16 (9), 554.

(11) El-Ali, J.; Sorger, P. K.; Jensen, K. F. Cells on chips. Nature 2006, 442 (7101), 403.

(12) Mehling, M.; Tay, S. Microfluidic cell culture. Current opinion in biotechnology 2014, 25, 95.

(13) Zhang, X.; Daou, A.; Truong, T. M.; Bertram, R.; Roper, M. G. Synchronization of mouse islets of Langerhans by glucose waveforms. Am J Physiol Endocrinol Metab 2011, 301 (4), E742.

(14) Dhumpa, R.; Truong, T. M.; Wang, X.; Roper, M. G. Measurement of the entrainment window of islets of Langerhans by microfluidic delivery of a chirped glucose waveform. Integr Biol (Camb) 2015, 7 (9), 1061. 
(15) Yi, L.; Wang, X.; Dhumpa, R.; Schrell, A. M.; Mukhitov, N.; Roper, M. G. Integrated perfusion and separation systems for entrainment of insulin secretion from islets of Langerhans. Lab Chip 2015, $15(3), 823$.

(16) Kellogg, R. A.; Gomez-Sjoberg, R.; Leyrat, A. A.; Tay, S. High-throughput microfluidic single-cell analysis pipeline for studies of signaling dynamics. Nature protocols 2014, 9 (7), 1713.

(17) Sumit, M.; Takayama, S.; Linderman, J. J. New insights into mammalian signaling pathways using microfluidic pulsatile inputs and mathematical modeling. Integr Biol (Camb) 2017, 9 (1), 6.

(18) Brooks, J. C.; Ford, K. I.; Holder, D. H.; Holtan, M. D.; Easley, C. J. Macro-to-micro interfacing to microfluidic channels using 3D-printed templates: application to time-resolved secretion sampling of endocrine tissue. Analyst 2016, 141 (20), 5714.

(19) Brooks, J. C.; Judd, R. L.; Easley, C. J. Culture and Sampling of Primary Adipose Tissue in Practical Microfluidic Systems. Methods Mol Biol 2017, 1566, 185.

(20) Clark, A. M.; Sousa, K. M.; Jennings, C.; MacDougald, O. A.; Kennedy, R. T. Continuous-flow enzyme assay on a microfluidic chip for monitoring glycerol secretion from cultured adipocytes. Anal Chem 2009, 81 (6), 2350.

(21) Dugan, C. E.; Grinias, J. P.; Parlee, S. D.; El-Azzouny, M.; Evans, C. R.; Kennedy, R. T. Monitoring cell secretions on microfluidic chips using solid-phase extraction with mass spectrometry. Anal Bioanal Chem 2017, 409 (1), 169.

(22) Godwin, L. A.; Brooks, J. C.; Hoepfner, L. D.; Wanders, D.; Judd, R. L.; Easley, C. J. A microfluidic interface for the culture and sampling of adiponectin from primary adipocytes. Analyst 2015, 140 (4), 1019.

(23) Inomata, N.; Toda, M.; Ono, T. Highly sensitive thermometer using a vacuum-packed Si resonator in a microfluidic chip for the thermal measurement of single cells. Lab Chip 2016, 16 (18), 3597.

(24) Li, X.; Brooks, J. C.; Hu, J.; Ford, K. I.; Easley, C. J. 3D-templated, fully automated microfluidic input/output multiplexer for endocrine tissue culture and secretion sampling. Lab Chip 2017, 17 (2), 341.

(25) Li, X.; Hu, J.; Easley, C. J. Automated microfluidic droplet sampling with integrated, mix-and-read immunoassays to resolve endocrine tissue secretion dynamics. Lab Chip 2018, 18 (19), 2926.

(26) Liu, Y.; Kongsuphol, P.; Chiam, S. Y.; Zhang, Q. X.; Gourikutty, S. B. N.; Saha, S.; Biswas, S. K.; Ramadan, Q. Adipose-on-a-chip: a dynamic microphysiological in vitro model of the human adipose for immune-metabolic analysis in type II diabetes. Lab Chip 2019, 19 (2), 241.

(27) Loskill, P.; Sezhian, T.; Tharp, K. M.; Lee-Montiel, F. T.; Jeeawoody, S.; Reese, W. M.; Zushin, P. H.; Stahl, A.; Healy, K. E. WAT-on-a-chip: a physiologically relevant microfluidic system incorporating white adipose tissue. Lab Chip 2017, 17 (9), 1645.

(28) Moraes, C.; Labuz, J. M.; Leung, B. M.; Inoue, M.; Chun, T. H.; Takayama, S. On being the right size: scaling effects in designing a human-on-a-chip. Integr Biol (Camb) 2013, 5 (9), 1149.

(29) Zhu, J.; He, J.; Verano, M.; Brimmo, A. T.; Glia, A.; Qasaimeh, M. A.; Chen, P.; Aleman, J. O.; Chen, $W$. An integrated adipose-tissue-on-chip nanoplasmonic biosensing platform for investigating obesity-associated inflammation. Lab Chip 2018, 18 (23), 3550.

(30) Vazquez-Vela, M. E.; Torres, N.; Tovar, A. R. White adipose tissue as endocrine organ and its role in obesity. Archives of medical research 2008, 39 (8), 715.

(31) Lafontan, M. Advances in adipose tissue metabolism. Int J Obes (Lond) 2008, 32 Suppl 7, S39.

(32) Negou, J. T.; Avila, L. A.; Li, X.; Hagos, T. M.; Easley, C. J. Automated Microfluidic Droplet-Based Sample Chopper for Detection of Small Fluorescence Differences Using Lock-In Analysis. Anal Chem 2017, 89 (11), 6153. 
(33) Negou, J. T.; Hu, J.; Li, X.; Easley, C. J. Advancement of analytical modes in a multichannel, microfluidic droplet-based sample chopper employing phase-locked detection. Anal Methods 2018, 10 (28), 3436.

(34) Herd, J. A.; Goodman, H. M.; Grose, S. A. Blood flow rates through adipose tissues of unanesthetized rats. Am J Physiol 1968, 214 (2), 263.

(35) Morrison, S.; McGee, S. L. 3T3-L1 adipocytes display phenotypic characteristics of multiple adipocyte lineages. Adipocyte 2015, 4 (4), 295.

(36) Dugan, C. E.; Cawthorn, W. P.; MacDougald, O. A.; Kennedy, R. T. Multiplexed microfluidic enzyme assays for simultaneous detection of lipolysis products from adipocytes. Anal Bioanal Chem 2014, 406 (20), 4851.

(37) Neuzi, P.; Giselbrecht, S.; Lange, K.; Huang, T. J.; Manz, A. Revisiting lab-on-a-chip technology for drug discovery. Nat Rev Drug Discov 2012, 11 (8), 620.

(38) Fruhbeck, G. Obesity: aquaporin enters the picture. Nature 2005, 438 (7067), 436.

(39) Geng, X.; Yang, B. Transport Characteristics of Aquaporins. Advances in experimental medicine and biology 2017, 969, 51.

(40) Hibuse, T.; Maeda, N.; Funahashi, T.; Yamamoto, K.; Nagasawa, A.; Mizunoya, W.; Kishida, K.; Inoue, K.; Kuriyama, H.; Nakamura, T.et al. Aquaporin 7 deficiency is associated with development of obesity through activation of adipose glycerol kinase. Proc Natl Acad Sci U S A 2005, 102 (31), 10993.

(41) Maeda, N.; Funahashi, T.; Hibuse, T.; Nagasawa, A.; Kishida, K.; Kuriyama, H.; Nakamura, T.; Kihara, S.; Shimomura, I.; Matsuzawa, Y. Adaptation to fasting by glycerol transport through aquaporin 7 in adipose tissue. Proc Natl Acad Sci U S A 2004, 101 (51), 17801.

(42) Marrades, M. P.; Milagro, F. I.; Martinez, J. A.; Moreno-Aliaga, M. J. Differential expression of aquaporin 7 in adipose tissue of lean and obese high fat consumers. Biochem Biophys Res Commun 2006, 339 (3), 785.

(43) Matsumura, K.; Chang, B. H.; Fujimiya, M.; Chen, W.; Kulkarni, R. N.; Eguchi, Y.; Kimura, H.; Kojima, H.; Chan, L. Aquaporin 7 is a beta-cell protein and regulator of intraislet glycerol content and glycerol kinase activity, beta-cell mass, and insulin production and secretion. Mol Cell Biol 2007, 27 (17), 6026.

(44) Bathany, C.; Beahm, D.; Felske, J. D.; Sachs, F.; Hua, S. Z. High throughput assay of diffusion through Cx43 gap junction channels with a microfluidic chip. Anal Chem 2011, 83 (3), 933.

(45) Benninger, R. K.; Hutchens, T.; Head, W. S.; McCaughey, M. J.; Zhang, M.; Le Marchand, S. J.; Satin, L. S.; Piston, D. W. Intrinsic islet heterogeneity and gap junction coupling determine spatiotemporal $\mathrm{Ca}(2)(+)$ wave dynamics. Biophysical journal 2014, 107 (11), 2723.

(46) Benninger, R. K.; Zhang, M.; Head, W. S.; Satin, L. S.; Piston, D. W. Gap junction coupling and calcium waves in the pancreatic islet. Biophysical journal 2008, 95 (11), 5048.

(47) Head, W. S.; Orseth, M. L.; Nunemaker, C. S.; Satin, L. S.; Piston, D. W.; Benninger, R. K. Connexin-36 gap junctions regulate in vivo first- and second-phase insulin secretion dynamics and glucose tolerance in the conscious mouse. Diabetes 2012, 61 (7), 1700.

(48) Burke, S.; Nagajyothi, F.; Thi, M. M.; Hanani, M.; Scherer, P. E.; Tanowitz, H. B.; Spray, D. C. Adipocytes in both brown and white adipose tissue of adult mice are functionally connected via gap junctions: implications for Chagas disease. Microbes and infection 2014, 16 (11), 893.

(49) Sheridan, J. D. Electrical coupling between fat cells in newt fat body and mouse brown fat. J Cell Biol 1971, 50 (3), 795.

(50) Bartness, T. J. Dual innervation of white adipose tissue: some evidence for parasympathetic nervous system involvement. J Clin Invest 2002, 110 (9), 1235.

(51) Bartness, T. J.; Bamshad, M. Innervation of mammalian white adipose tissue: implications for the regulation of total body fat. Am J Physiol 1998, 275 (5), R1399. 
(52) Jiang, H.; Ding, X.; Cao, Y.; Wang, H.; Zeng, W. Dense Intra-adipose Sympathetic Arborizations Are Essential for Cold-Induced Beiging of Mouse White Adipose Tissue. Cell Metab 2017, 26 (4), 686.

(53) Youngstrom, T. G.; Bartness, T. J. Catecholaminergic innervation of white adipose tissue in Siberian hamsters. Am J Physiol 1995, 268 (3 Pt 2), R744.

(54) Zeng, W.; Pirzgalska, R. M.; Pereira, M. M.; Kubasova, N.; Barateiro, A.; Seixas, E.; Lu, Y. H.; Kozlova, A.; Voss, H.; Martins, G. G.et al. Sympathetic neuro-adipose connections mediate leptin-driven lipolysis. Cell 2015, 163 (1), 84.

(55) Getty, L.; Panteleon, A. E.; Mittelman, S. D.; Dea, M. K.; Bergman, R. N. Rapid oscillations in omental lipolysis are independent of changing insulin levels in vivo. J Clin Invest 2000, 106 (3), 421.

(56) Cheong, R.; Levchenko, A. Oscillatory signaling processes: the how, the why and the where. Current opinion in genetics \& development 2010, 20 (6), 665.

(57) Erickstad, M.; Gutierrez, E.; Groisman, A. A low-cost low-maintenance ultraviolet lithography light source based on light-emitting diodes. Lab Chip 2015, 15 (1), 57.

(58) Brooks J.C., J. R. L., Easley C.J. Culture and Sampling of Primary Adipose Tissue in Practical Microfluidic Systems; Humana Press: New York, NY, 2017.

(59) Deal, K. S.; Easley, C. J. Self-regulated, droplet-based sample chopper for microfluidic absorbance detection. Anal Chem 2012, 84 (3), 1510.

(60) Gruner, P.; Riechers, B.; Semin, B.; Lim, J.; Johnston, A.; Short, K.; Baret, J. C. Controlling molecular transport in minimal emulsions. Nat Commun 2016, 7, 10392.

(61) Godwin, L. A.; Pilkerton, M. E.; Deal, K. S.; Wanders, D.; Judd, R. L.; Easley, C. J. Passively operated microfluidic device for stimulation and secretion sampling of single pancreatic islets. Anal Chem 2011, 83 (18), 7166.

(62) Song, H.; Ismagilov, R. F. Millisecond kinetics on a microfluidic chip using nanoliters of reagents. Journal of the American Chemical Society 2003, 125 (47), 14613. 


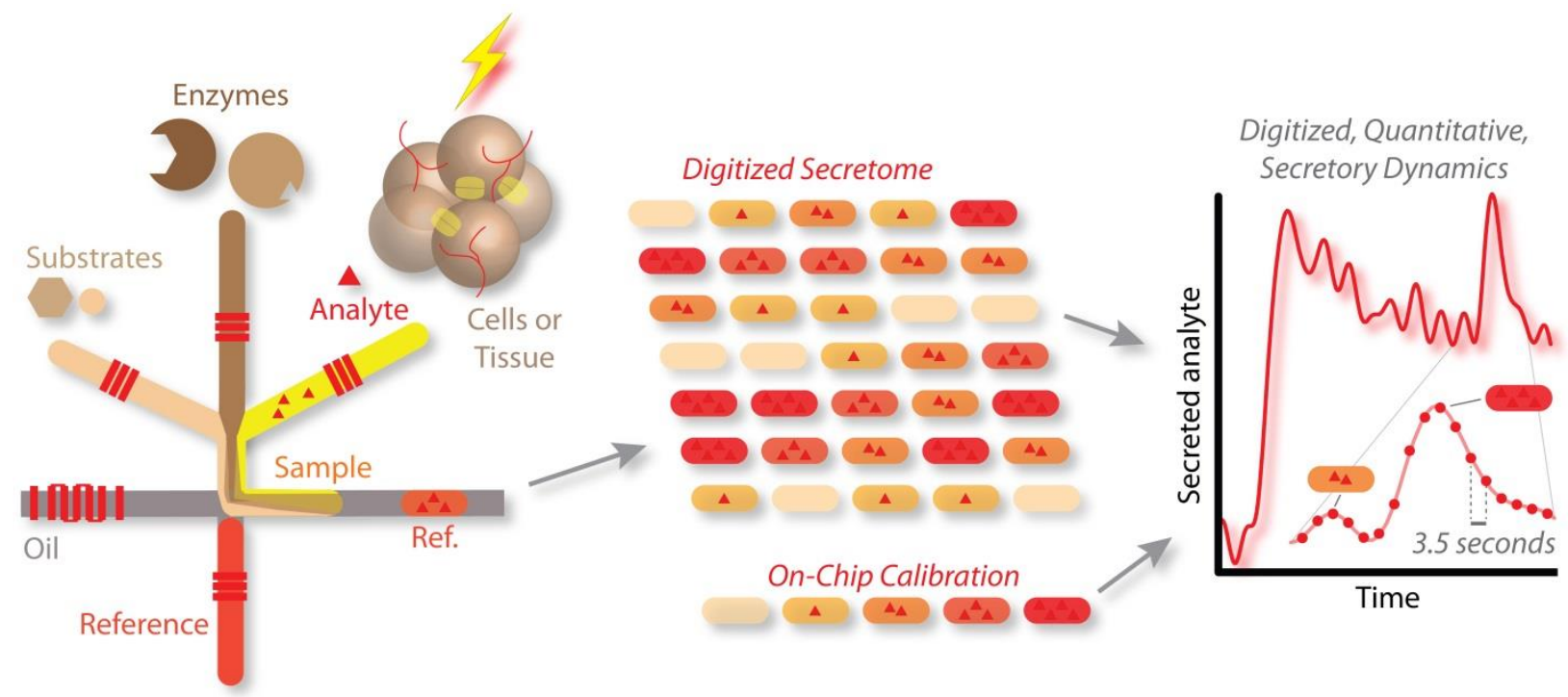

Figure 1. High temporal resolution sampling and quantitative detection of glycerol secretion dynamics from adipose tissue using our automated, droplet-based microfluidic system. The microdevice formed droplets by active pumping with on-chip valves (red lines over channels). Substrates, enzymes, and standards/samples were loaded into the top three inlets for sample droplet formation, and $85 \mu \mathrm{M}$ resorufin was used as the reference (lower inlet). Perfluorocarbon oil with surfactant (left inlet) was used to segment and isolate droplets. Glycerol secretions from tissue or cells were stored in the 2.6-nL sample droplets, effectively digitizing the secretory trace in time. Sample and reference droplets were generated alternatively every $3.5 \mathrm{~s}$ each then sequentially passed by the optical window for lock-in detection and calibration. Enzyme assay fluorescence was measured and converted into glycerol amounts using a similarly digitized calibration curve. 
A

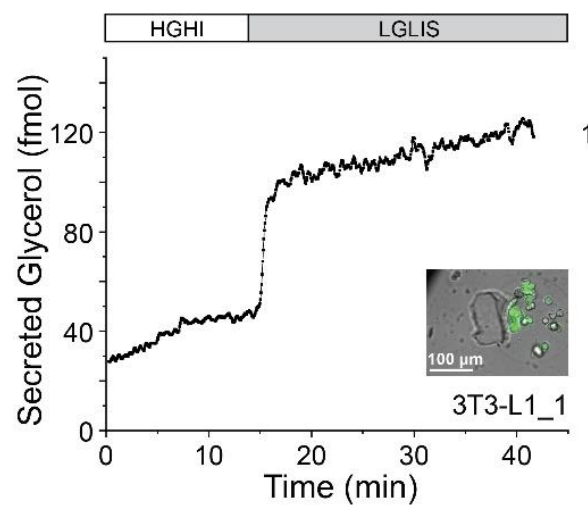

B

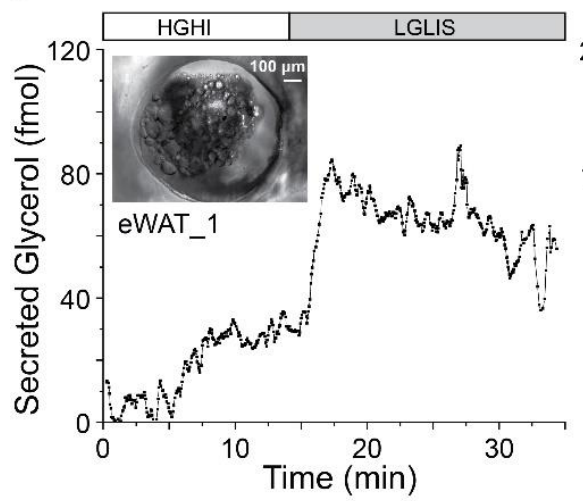

C

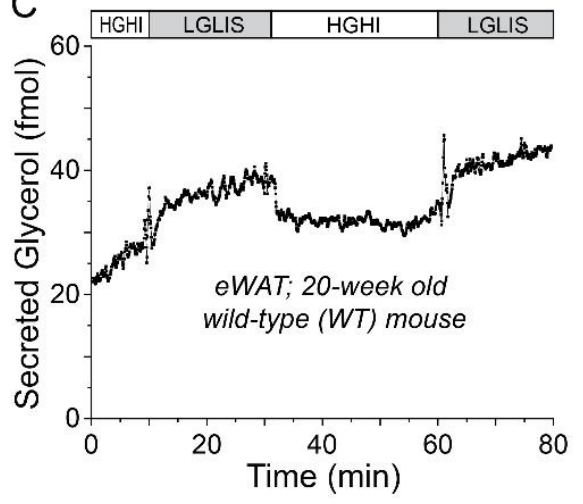

3T3-L1 adipocyte spheroids
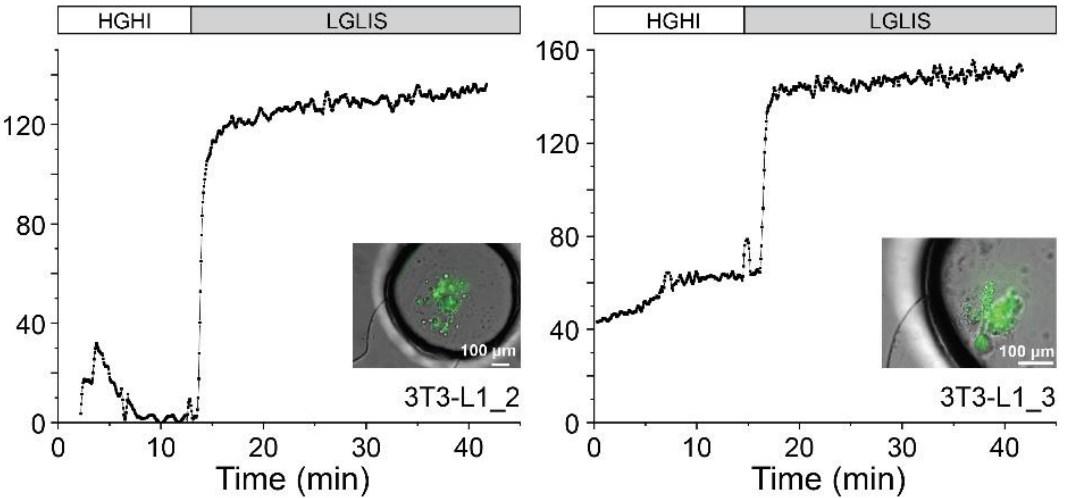

eWAT explants (12-week old mice)
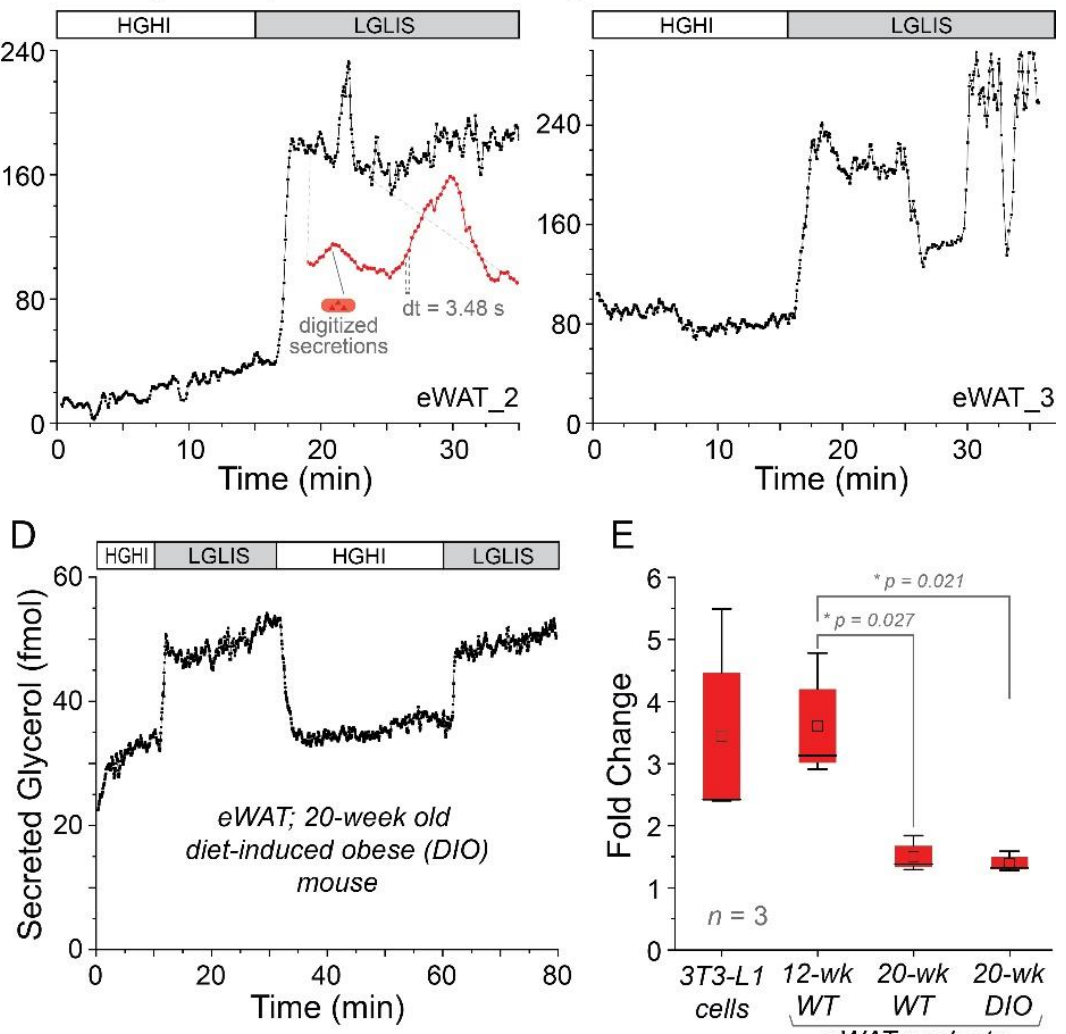

E

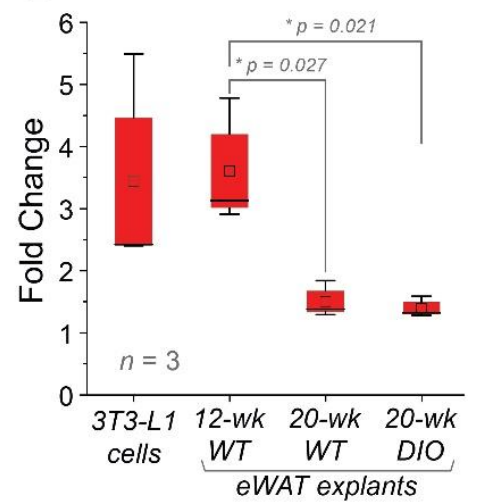

Figure 2. High resolution temporal sampling and quantification of glycerol secretions from adipocyte spheroids and adipose tissue explants. A) Glycerol release from 3T3-L1 adipocyte spheroids responded quickly, with sustained release rates before and after treatments. Insets show merged DIC and fluorescence images of stained adipocytes in the spheroids. B) By contrast, glycerol release from primary murine eWAT explants (12-week old mice) was observed to both increase and to oscillate. The middle frame (eWAT_2) shows a zoomed version of several bursts captured by a series of droplets sampled at $\mathrm{dt}=3.48$ seconds. C) Glycerol release from eWAT explants from 20week old mice was less pronounced, more akin to 3T3-L1 cell spheroids. D) Similar patterns were seen from explants of 20-week old dietinduced obese (DIO) mice. E) Compiled fold changes of the sustained glycerol release from the 3T3-L1 cell spheroids and the three 
different types of eWAT explants after changing the treatment from the HGHI to LGLIS. "HGHI" $=25$ mM glucose, 2 nM insulin in DMEM, with 0.25\% BSA; "LGLIS" = 3 mM glucose, 50 pM insulin, with $20 \mu \mathrm{M}$ isoproterenol in DMEM, with $0.25 \%$ BSA.

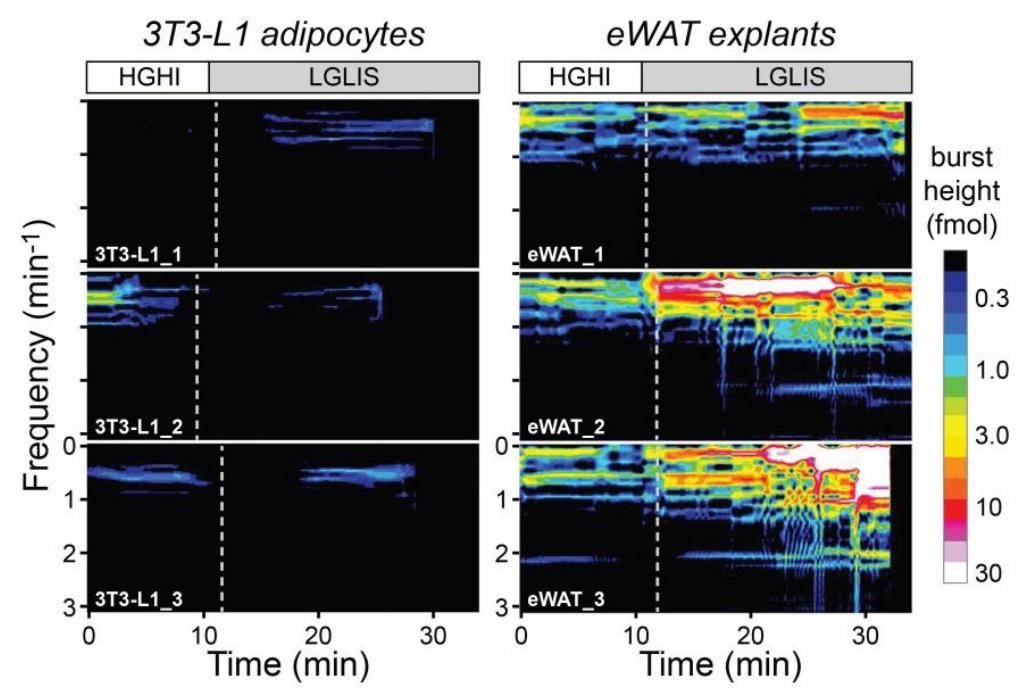

Figure 3. Unique oscillation analysis of glycerol release (FFT spectrograms) enabled by microfluidic droplet sampling. eWAT explants exhibited treatment-responsive oscillations in glycerol release in the frequency range of 0.2 to $2.0 \mathrm{~min}^{-1}$ (periods from $\sim 30$ to $300 \mathrm{~s}$ ), while 3T3-L1 adipocyte spheroids were essentially quiet. Vertical dashed lines depict the exact treatment times. The legend at right shows glycerol burst intensity on a logarithmic scale with a "16-color" colormap. 

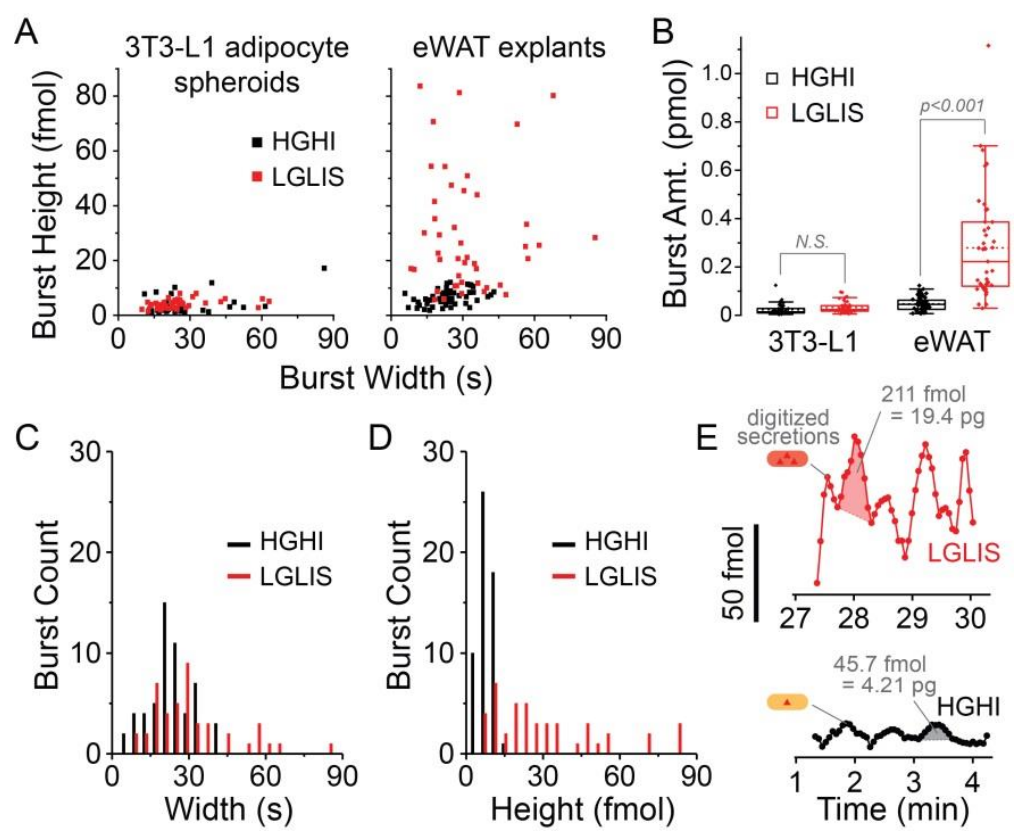

Figure 4. Glycerol burst analysis enabled by high-resolution data. A) Peak analysis software extracted burst heights (fmol) and burst widths (s). Data from 3T3-L1 cells spheroids or eWAT explants is presented under different treatments. Only explants showed significant treatment-dependent changes in burst height. B) Peak areas were used to extract burst amounts, again showing a significant treatmenttriggered change only in eWAT explants. Mean burst amounts increased about 6-fold from $\sim 50 \mathrm{fmol}$ at HGHI to $300 \mathrm{fmol}$ per burst under LGLIS treatment. C) Histograms of eWAT glycerol bursts showed little change in width but D) a significant increase in burst height after stimulation. E) Data excerpts from Fig. 2B (eWAT_3) are shown at higher magnification with examples of resolved glycerol bursts and calculated burst amounts. Note: Oscillation peaks' full-widths at half-maximum (FWHM) were used as a metric for burst widths. 

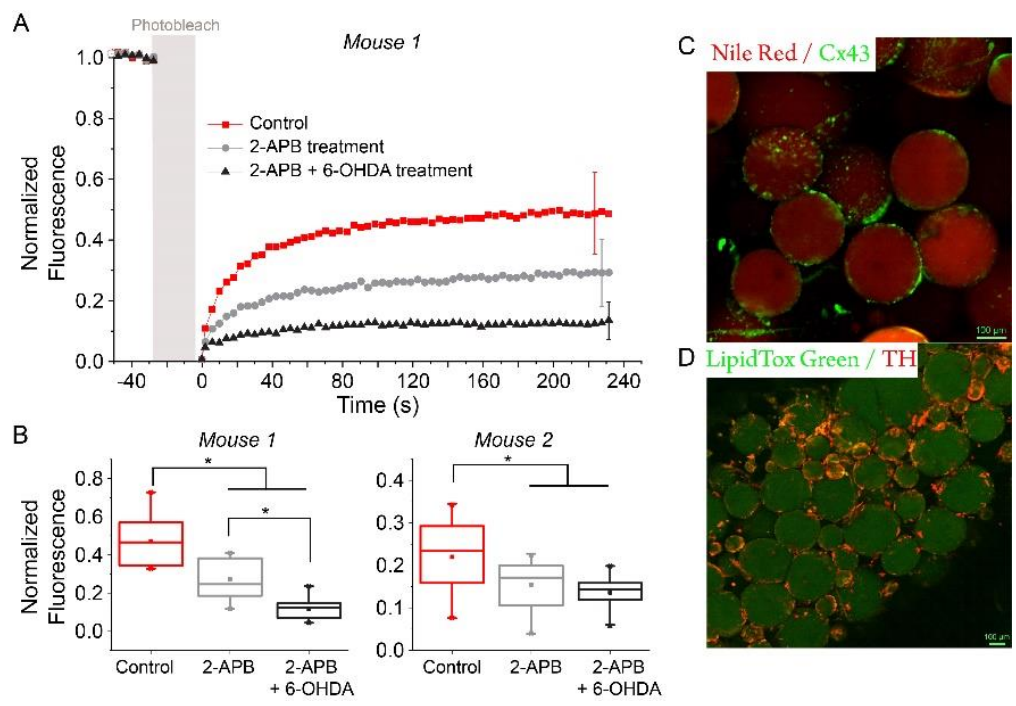

Figure 5. Evidence for cell-to-cell connectivity in adipose tissue explants via confocal fluorescence microscopy. A) Fluorescence recovery after photobleaching (FRAP) was used to monitor exchange between individual adipocytes in the tissue. Control (buffer), 2-APB, or 2APB plus 6-OHDA treatments were applied to eWAT explants, and results suggest that disrupting gap junctions or nerve signaling reduces the dye recovery. FRAP was done on 2-3 pieces of tissue per mouse on $>9$ different spots per explant. B) Fluorescence recovery rate comparison under different treatments; tissue samples from two mice. Data from 125 to $230 \mathrm{~s}$ in A were chosen and analyzed. ${ }^{*}, P$-value $<$ 0.05. C) Immunostaining of adipose tissue gap junctions. Nile red stains the lipid droplets in adipocytes (red), and gap junction alpha-1 protein (Cx43) is immunostained in green. D) Immunostaining of adipose tissue neurons. LipidTox Green stains the lipid droplets in adipocytes (green), and Tyrosine hydroxylase (TH) is immunostained in red. TH is marker of sympathetic neuron terminals. Note: Error bars in A report standard deviations, and bars represent error within each trace of the same color. 

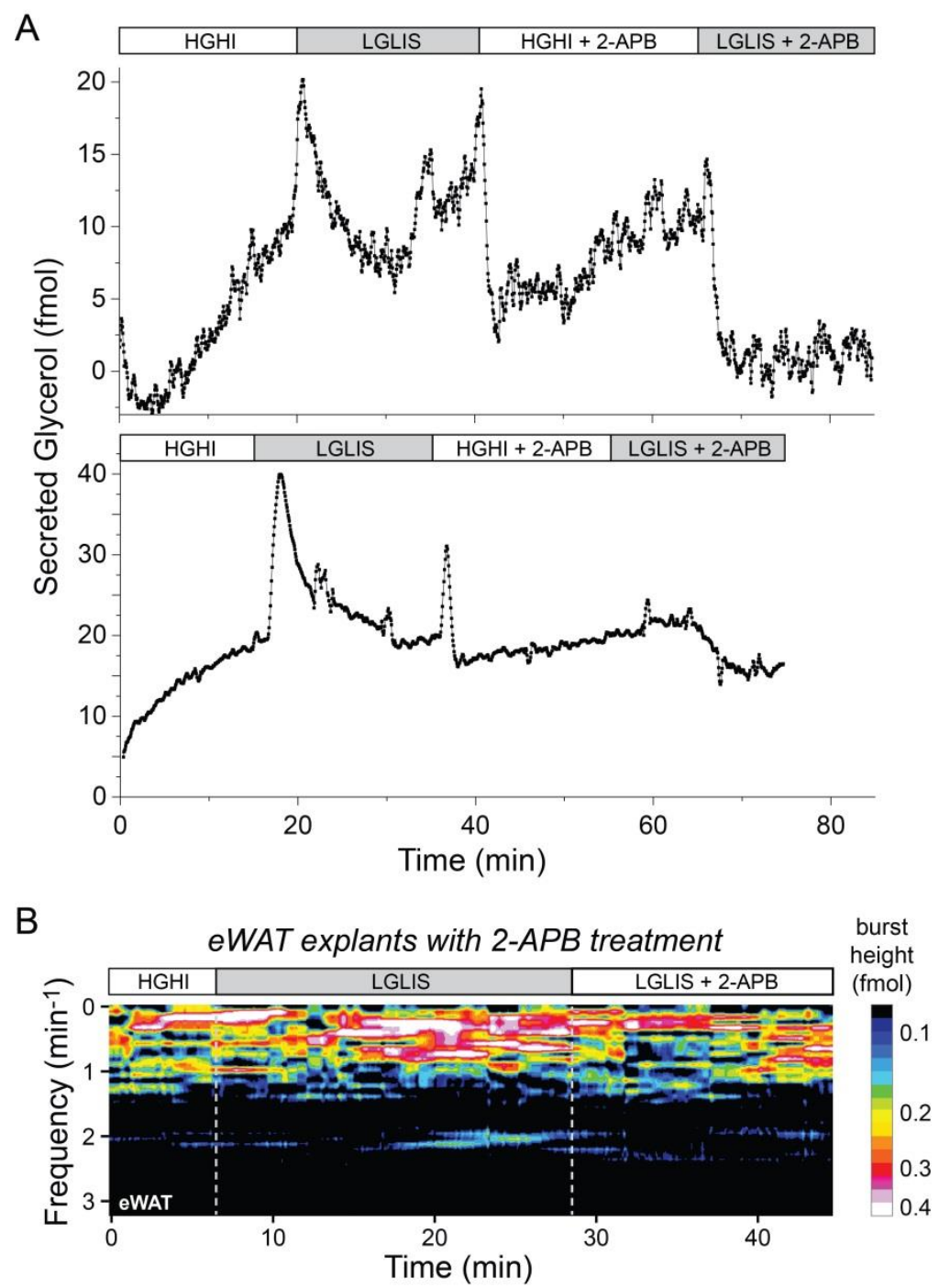

Figure 6. Evidence for cell-to-cell connectivity in adipose tissue explants. A) Glycerol release from eWAT explants (12-and 17-week ages, respectively) treated sequentially by HGHI, LGLIS, HGHI + $100 \mu \mathrm{M} 2$-APB, and LGLIS $+100 \mu \mathrm{M} 2$-APB. Stimulatory conditions enhanced glycerol secretion as usual, but a gap junction inhibitor drug (2-APB) prevented stimulatory effects upon the second treatment. B) An FFT spectrogram shows oscillatory bursts of glycerol were amplified by stimulation with LGLIS, while 2-APB treatment caused a loss of oscillatory magnitude even in the presence of the stimulant, with an apparent preference toward loss of higher frequency oscillations. 


\section{Supplementary Information}

Methods

\section{Materials and Reagents}

Deionized water was produced by Barnstead ${ }^{\mathrm{TM}}$ MicroPure $^{\mathrm{TM}}$ Water Purification system (ThermoFisher Scientific, serial No. 42034239 ) with the resistance value as $18.2 \mathrm{M} \Omega \cdot \mathrm{cm}$ at $23.5^{\circ} \mathrm{C}$ and particles less than $0.2 \mu \mathrm{m}$. All of buffers in the experiments were prepared with deionized water. SYLGARD ${ }^{\circledast} 184$ silicone elastomer kits (Dow Corning, Midland, MD) were used to make polydimethylsiloxane (PDMS) devices, with the kit containing elastomer base and curing agent. Silicon wafers were purchased from the Polishing Corporation of America (Santa Clara, CA). Negative photoresists, SU-8 2015 and SU-8 2050, were from Microchem (Westborough, MA); and positive photoresist, AZ 40XT-11D, was obtained from AZ Electronic Materials USA (Somerville, NJ). Heat inactivated HyClone ${ }^{\mathrm{Tm}}$ Fetal Bovine Serum (FBS) was from Gel Healthcare Life Sciences, and Hanks' Balanced Salt Solution (HBSS) was purchased from Lonza. D-glucose, HEPES (4-2-hydroxyethyl-1-piperazineethanesulfonicacid), penicillin-streptomycin, $\mathrm{NaCl}, \mathrm{CaCl}_{2} \cdot 2 \mathrm{H}_{2} \mathrm{O}, \mathrm{KCl}, \mathrm{MgCl}_{2} \cdot 6 \mathrm{H}_{2} \mathrm{O}, \mathrm{resorufin}$ sodium salt, cholortrimethylsilane, agarose (ultra-low gelling temperature, molecular biology grade), human insulin solution, 3-Isobutyl-1methylxanthine, dexamethasone, and Glycerol Assay Kit (catalog\#: MAK117-1KT) were purchased from Sigma-Aldrich (St. Louis, MO). Human insulin concentration was confirmed by protein absorbance at $280 \mathrm{~nm}\left(\mathrm{~A}_{280}\right)$ using a NanoDrop 1000 spectrophotometer (ThermoFisher). Isoproterenol hydrochloride ( $>98 \%$, purity), Bovine serum albumin (BSA), and Accutase cell detachment solution were from VWR (West Chester, PA). Dulbecco's Modified Eagle Medium (DMEM; low glucose, L-glutamine, sodium pyruvate, and phenol red; catalog \# 11885084), DMEM (no glucose, no glutamine, no phenol red; catalog \# A11430-01), MEM Non-Essential Amino Acids Solution (100X; catalog\# 111400502), Sodium Pyruvate (100 mM; catalog \# 11360070), Fetal Bovine Serum (qualified, USDA-approved regions; catalog \# 10437010), Penicillin-Streptomycin (10,000 U/mL; catalog \# 15140122), and Dulbecco's Phosphate Buffered Saline (DPBS) were all purchased from ThermoFisher Scientific (Grand Island, NY). Pico-Surf surfactant (2\% in Novec 7500) was purchased from Dolomite Microfluidics (Norwell, MA). Novec ${ }^{\mathrm{TM}} 7500$ Engineered Fluid (HFE 7500) was obtained from 3M. Connexin 43 (gap junction) monoclonal antibody (CX-1B1) labeled by Alexa Fluor 488 (cat. \# 138388), Image-IT Fixative solution (4\% formaldehyde in PBS, methanol-free), proteinase K solution (20 mg/mL), HCS LipidTox Green Neutral Lipid Stain reagent (1000X) for cellular imaging, HCS LipidTox Red phospholipidosis detection reagent (10000X), 5-carboxyfluorescein diacetate acetoxymethyl ester (5-CFDA AM) were also purchased from ThermoFisher. TH Antibody (F-11) Alexa Fluor ${ }^{\mathrm{TM}} 594$ (catalog \# sc-25269), 6-Hydroxydopamine hydrobromide (CAS 636-00-0), and Nile Red (CAS: 7385-67-3) were obtained from Santa Cruz Biotechnology (Dallas, TX). 


\section{Fabrication of master wafers}

Microdevice photomasks were designed in Adobe Illustrator and printed at Fineline Imaging (Colorado Spring, CO) at 50,800 DPI resolution. The microfluidic device design includes two layers: the pneumatic valve control channels are on the bottom layer, and the fluidic flow channels are in the upper layer. Three masks were designed to allow two depths of fluidic channels (black and orange channels in Fig. S-1A) and one pneumatic control layer (red channels in Fig. S-1A). Master wafers for molding these devices were fabricated by commonly used photolithography. Silicon wafers were ready to use after shaking in diluted sulfuric acid (1 M) at $220 \mathrm{rpm}$ for $30 \mathrm{~min}$, washing and shaking in D.I. water for $30 \mathrm{~min}$, then drying by an air stream.

For the pneumatic control layer, negative photoresist (SU-8 2015) was spin-coated onto the wafer at $2000 \mathrm{rpm}$ for 45 seconds ( 20 $\mu \mathrm{m}$ thickness), followed by soft baking on a hotplate for $5 \mathrm{~min}$ at $95^{\circ} \mathrm{C}$, then passive slow cooling to room temperature. UV exposure through the photomask was carried out for $2 \min \left(\sim 200 \mathrm{~mJ} / \mathrm{cm}^{2}\right)$ by an in-house built ultraviolet lithography light source ${ }^{57}$, and the wafer was then hard baked for $5 \mathrm{~min}$ at $95^{\circ} \mathrm{C}$ then developed in SU-8 developer solution for 7 min, making it ready for molding PDMS devices.

For the fluidic flow layer, both negative and positive photoresists were patterned on the same silicon wafer to give a two-depth master. As shown in Fig. S-1A, the black channels represent the channels that cross over the valves, which are semi-circular in cross-section to allow valve closing; the mold for these channels was fabricated by AZ40XT-11D. Downstream incubation channels (orange) were made by molding from SU-8 2050 of rectangular cross-section, which is more appropriate for imaging droplets. The negative photoresist layer was fabricated first. SU-8 2050 was spin-coated on the pretreated wafer at $3000 \mathrm{rpm}$ for $45 \mathrm{~s}(\sim 50 \mu \mathrm{m}$ thickness $)$, followed by a soft bake on a hotplate for $5 \mathrm{~min}$ at $95^{\circ} \mathrm{C}$, then a slow cooling step. UV exposure through the photomask was carried out for $2 \mathrm{~min}\left(\sim 200 \mathrm{~mJ} / \mathrm{cm}^{2}\right)$, a hard bake was done for $5 \mathrm{~min}$ at $95^{\circ} \mathrm{C}$, and the wafer was then treated by SU-8 developer for $7 \mathrm{~min}$. After this pattern was developed, the wafer was put in an oven for $30 \mathrm{~min}$ at $60^{\circ} \mathrm{C}$. The second layer was then fabricated using positive photoresist (AZ40XT-11D). This photoresist was passively warmed to room temperature, spin-coated onto the wafer at $2000 \mathrm{rpm}$ for $45 \mathrm{~s}$, then soft baked on a hotplate ( 5 $\min$ at $65^{\circ} \mathrm{C}, 5 \mathrm{~min}$ at $95^{\circ} \mathrm{C}$, and $5 \mathrm{~min}$ at $115^{\circ} \mathrm{C}$ ). The wafer was then allowed to cool down to room temperature very slowly. The fluidic photomask was aligned with the SU-8 patterns on the AZ photoresist-coated wafer, and this was exposed to UV for $90 \mathrm{~s}\left(\sim 153 \mathrm{~mJ} / \mathrm{cm}^{2}\right) . \mathrm{A}$ post-exposure bake was done on the hotplate for $5 \mathrm{~min}$ at $65^{\circ} \mathrm{C}, 5 \mathrm{~min}$ at $95^{\circ} \mathrm{C}$, and $90 \mathrm{~s}$ at $105^{\circ} \mathrm{C}$. This wafer was also cooled passively to room temperature then developed in $\mathrm{AZ}$ developer solution for $6 \mathrm{~min}$. The last step was the reflow of $\mathrm{AZ}$ photoresist to create a semicircular cross-section, which was done by heating the wafer on a hotplate for $10 \mathrm{~min}$ at $120{ }^{\circ} \mathrm{C}$ under the partial cover of petri dish. Ultimately, the negative photoresist layer was $\sim 50 \mu \mathrm{m}$ in thickness (orange channels in Fig. S-1A), and the positive photoresist layer was $\sim 40 \mu \mathrm{m}$ thick (black channels in Fig. S-1A). After the photolithography was done, the two wafer masters were ready to use for device molding. 


\section{Microchip fabrication}

The photoresist-patterned silicon molds were exposed to chlorotrimethylsilane (TMCS) vapor for 30 min before the soft lithography of PDMS. One batch of PDMS precursor and curing agent was mixed at the ratio of 20:1, $10.5 \mathrm{~g}$ in total, and degassed and then spin coating on the valve channel master in the speed of $2400 \mathrm{rpm}$ for $45 \mathrm{~s}$. At the same time, another batch of PDMS prepolymers were mixed at the ratio of 5:1, $36 \mathrm{~g}$ in total, and degassed and poured on the flowing channel master. Both were baked at $60{ }^{\circ} \mathrm{C}$ for 30 min in the oven, and the flow channel bulk chip were cut and aligned to the valve channel under observation by microscopy at 3X magnification. The PDMS was baked for another 4 hours in the oven. After PDMS stamps were peeled off the wafers, inlets and outlets punched with Miltex disposable biopsy punches, then the chips were washed by methanol, air dried, and irreversibly bound to the a cover slide ( $24 \mathrm{~mm} \times 40 \mathrm{~mm}$ with 0.13 $0.16 \mathrm{~mm}$ thickness) by plasma oxidization. The two-layer microchips were ready to use after thermally aging at $60{ }^{\circ} \mathrm{C}$ overnight to minimize uncured PDMS monomer leakage.

\section{3D-printed templates for the fabrication of cell culture reservoirs}

3D-printed templates and inserts used in device fabrication and experiments were designed in the 3D modelling computer program, SketchUp 2017, and printed by a MakerBot Replicator 2 with PLA (polylactic acid) filament (HatchBox PLA, 1.75 mm diameter). The $\mathrm{CAD}$ design of $3 \mathrm{D}$ molds for the fabrication of cell culture reservoirs is shown in Fig. S-1B (gray). During microchip fabrication (as described above), a 3D template was aligned with the wafer mold for the flow channel after pouring PDMS over the wafer, and the entire assembly was cured in the oven. After the bulk PDMS was peeled off from the 3D template and wafer, the cell culture reservoir was formed with 1.5-mm thick PDMS below the reservoir. A 0.75-mm ID punch (69039-07, Electron Microscopy Sciences, Hatfield, PA) was used to create a via between the tissue trapping/culturing reservoir and the inlet microfluidic channel for droplet sampling.

\section{Automated flow control system with pneumatic valving}

The 18 pneumatic control valves in the microfluidic chip were driven by solenoid switches (LHDA0533115H, the Lee Company, Westbrook, CT) assembled on a metal manifold and under the control of a data acquisition device (PCI-6259, National Instrument, Austin, TX) driven by LabVIEW programming software. A valve driver circuit was used as the buffer and current amplifier between the PCI and solenoid switches. A house nitrogen gas source was used to actuate these pneumatic solenoid valves by 26-psi pressure adjusted by a pressure regulator. The control valves on the microchip were connected to the corresponding solenoid valve with 90-degree angled 22 gauge blunt syringe needles (Jensen Global JG22-0.5HPX-90, Santa Barbara, CA) through Tygon microbore tubing (0.02" I.D. X 0.06" O.D., Cole-Parmer, Vernon Hills, IL). The valve inlets interfaced with the control system were punched by 0.75-mm ID punch (69039-07, Electron Microscopy Sciences, Hatfield, PA). An in-house written LabVIEW application was used to control the actuation of the valves. 
When a valve was set in closed status, the solenoid switch was activated to pressurize the nitrogen gas into the dead-end channel of the control layer to deflect the PDMS membrane up and close the fluidic channel in the upper layer (i.e. push-up style valves). Control layer channels were dead-end-filled with deionized water to avoid air permeation through the PDMS membranes and into fluidic channels.

Microvalve pumping was controlled through LabVIEW using a 5-step pumping cycle, shown in Fig. S-3 and supplementary video S-1. A pair of sample and reference droplets were formed by cycling through sample pumping, oil pumping, reference pumping, and oil pumping sequentially. The droplet size was controlled precisely by on-chip valves ${ }^{25,33}$, using the number of pumping cycles, and was chosen with consideration for the width of the incubation channel, since a widened "pancake" shape of droplets in the incubation channel facilitates microscopic imaging through a constant optical path length. Droplets with smaller size than the channel width flowed through the channel at different rates, and droplet order could be undesirably altered with small droplets. Since the volume for each pumping cycle is highly consistent, droplets could be generated at precise volumes. As shown in Fig. S-6, droplet sizes during a 50-minute test experiment were highly stable, with a deviation less than $1.5 \%$. For all experiments reported in the paper, sample and reference solutions were each pumped through LabVIEW control to give 0.287 droplets s$^{-1}$ (one droplet every $3.48 \mathrm{~s}$ ), and oil segments were pumped at 0.575 segments s${ }^{-1}$ (two segments every $3.48 \mathrm{~s})$. This programming produced droplets with average volumes of $2.58 \pm 0.04 \mathrm{~nL}(\% \mathrm{CV}=1.5 \%)$ for the sample droplets and $2.18 \pm 0.04 \mathrm{~nL}$ for the reference droplets (different volumes were intentional).

\section{Extraction of murine epidydimal adipose tissue (eWAT)}

C57BL/6J male mice of different types from Jackson Laboratories were used in this project. All animal experiments were done in

compliance with relevant laws and institutional guidelines, and protocols (2017-3101) were approved by the institutional animal care and use committee (IACUC) of Auburn University. 9-, 12-, and 17-week old male mice; 20-week old wild-type mice; and 20-week old dietinduced obese (DIO) mice were used in the experiments. Epidydimal white adipose tissue (eWAT) pads were extracted from mice as described in previous papers ${ }^{18,24}$. After extraction, they were transferred into $10 \mathrm{~mL}$ of phosphate-HEPES buffer (10 mM HEPES, 135.3 $\mathrm{mM} \mathrm{NaCl}, 2.2 \mathrm{mM} \mathrm{CaCl}_{2} \cdot 2 \mathrm{H}_{2} \mathrm{O}, 1.2 \mathrm{mM} \mathrm{MgSO}_{4} \cdot 7 \mathrm{H}_{2} \mathrm{O}, 0.4 \mathrm{mM} \mathrm{KH}_{2} \mathrm{PO}_{4}, 2.2 \mathrm{mM} \mathrm{Na}_{2} \mathrm{HPO}_{4}, 0.4$ mM D-glucose, 2\% BSA, pH 7.4). Fat pads were placed in a $60 \mathrm{~mm}$ Petri dish with phosphate-HEPES buffer, and extra vasculature was removed by Iris micro dissecting scissors. $2 \mathrm{~mm}$ explants were punched from fat pads by a $2 \mathrm{~mm}$ sterile disposable biopsy punch and collected into a glass tube with $4 \mathrm{~mL}$ phosphateHEPES buffer. The explants were washed by the buffer 3 times by centrifuging at $1000 \mathrm{rpm}$ for $3 \mathrm{~min} .3 \mathrm{~mL}$ buffer was removed by the syringe after centrifuging, and $3 \mathrm{~mL}$ fresh buffer was added for washing. Then the phosphate-HEPES buffer was changed to fat serum media (DMEM + low glucose and phenol red with $12 \%$ fetal bovine serum, 120 units $/ \mathrm{mL}$ Nystatin, 120 units/mL Penicillin-Streptomycin and 1.2X MEM NEAA), and the explants were washed in the media another 2 times. After washing, the explants were placed in the sterile 96-well plate with $200 \mu \mathrm{L}$ fat serum media and 3D-printed anchor to counteract the buoyancy of the fat tissue, with each piece of explant in 
one well. The explants were cultured in the $37^{\circ} \mathrm{C}$ incubator with $5 \% \mathrm{CO}_{2}$, which can be maintained up to $7-10$ days if the serum media is refreshed twice per day. The explant for each experiment was pretreated in high glucose $(25 \mathrm{mM})$ and high insulin $(2 \mathrm{nM}) \mathrm{DMEM}$ media without serum for $30 \mathrm{~min}$ before loading onto the microchip.

\section{3T3-L1 cell culture, differentiation, and encapsulation}

3T3-L1 fibroblasts (CL-173) were obtained from American Type Culture Collection (ATCC, Manassas, VA) and cultured in DMEM media with $10 \% \mathrm{FBS}$ to $100 \%$ confluency in $25 \mathrm{~cm}^{2}$ cell culture flask. Following this, an adipogenic cocktail (DMEM $+10 \%$ FBS with 0.5 $\mathrm{mM} 3$-isobutyl-1-methylxanthine, $250 \mathrm{nM}$ dexamethasone, and $8.9 \mu \mathrm{g} / \mathrm{mL}$ insulin) was used to culture the cells for 4 days, and then the differentiation media was removed and changed to insulin media (DMEM $+10 \%$ FBS with $8.9 \mu \mathrm{g} / \mathrm{mL}$ insulin) to culture the cells for another 3 days. The 3T3-L1 adipocytes were used in the sixth day after differentiation. Adipogenesis of cells was validated by visualization of lipid droplet accumulation and staining of lipid droplets (Fig. S-8). Applying our device that is geared toward sampling tissue explants instead for glycerol secretion sampling from a cell line required that the adipocyte cells be interfaced to the microfluidic reservoir. However, it is difficult to manipulate single cells or small numbers of cells in this way. For this reason, we developed a method-using the same microfluidic device—-to encapsulate 3T3-L1 adipocyte cells into agarose droplets to form 3D spheroids of cells with around $200 \mu \mathrm{m}$ diameter (see Fig. S-9 and supplementary video 2). Once gelled, these spheroids could then be easily loaded into and removed from the cell culture reservoir by pipetting—akin to manipulating adipose explants ${ }^{58}$ or pancreatic islets ${ }^{25}$.

To accomplish encapsulation, culture media was first removed, and the cells were washed by $4 \mathrm{~mL}$ DPBS three times. $2 \mathrm{~mL} 1 \mathrm{X}$ LipidTox Green in DPBS was added into the flask and incubated at $37^{\circ} \mathrm{C}$ for $30 \mathrm{~min}$, and cellular imaging was collected through the FITC channel of a Nikon Ti-E fluorescence microscope. Staining solution was removed, and cells were washed by $4 \mathrm{~mL}$ DPBS three times. Cell detachment from the cell culture flask was induced by incubating cells with $2 \mathrm{~mL}$ Accutase cell detachment solution at $37^{\circ} \mathrm{C}$ for $10 \mathrm{~min}$. The cell suspension was transferred from the flask to $15 \mathrm{~mL}$ sterile conical tube and centrifuged at $1000 \mathrm{rpm}$ for $3 \mathrm{~min}$, then the upper layer of solution was aspirated, and the cell pellet was resuspended in $200 \mu \mathrm{L}$ cell culture media. Around $10 \mu \mathrm{L}$ of cell suspension was loaded in the second inlet on the microfluidic device. $0.125 \mathrm{~g}$ agarose (ultra-low gelling temperature) was dissolved in $10 \mathrm{~mL}$ DPBS by heating in a microwave for $15 \mathrm{~s}$ to make $1.25 \%$ agarose solution. The agarose gel solution was loaded in the first and third inlets on the dropletgenerating device (inlet1 and inlet3 in Fig. S-1). HFE7500 with 0.5\% Pico-Surf was utilized as the oil phase and loaded in the oil inlet. The in-house written LabVIEW program was set to run with $350 \mathrm{~ms}$ of sample pumping time for 20 sample pump cycles, and $450 \mathrm{~ms}$ of oil pump time for 2 oil pump cycles. The cells, now encapsulated in agarose droplets, were collected in the reference inlet which was set as the outlet in this specific application (long incubation channel not used here). The agarose droplet suspension was chilled on ice for 3 min to induce gel formation, then the droplet layer (upper layer) was transferred to adipocyte insulin media in a $3 \mathrm{~mL}$ Petri dish and conserved in 
the $37^{\circ} \mathrm{C}$ incubator with $5 \% \mathrm{CO}_{2}$ until use. We found that adipocytes could be cultured within the gel for up to one week. Cell viability was usually reduced by about $15 \%$ after passing through the microvalves, which was estimated through cell viability test with a hemocytometer and $0.2 \%$ trypan blue for cell staining.

\section{Glycerol release measurement, image acquisition, and analysis}

The microfluidic chip was set up on the stage of a fluorescence microscope mounted with a Tokai Hit stage top incubator, with D.I. water back-filled into the microchip valve inlets. All experiments were operated at $37^{\circ} \mathrm{C}$ in the incubator. For the standard curve of glycerol assay on the microfluidic device, $1 \mu \mathrm{L}$ of dye reagent and $1 \mu \mathrm{L}$ of ATP from the glycerol assay kit were mixed with $135 \mu \mathrm{L}$ glycerol assay buffer from the glycerol assay kit with $0.25 \% \mathrm{BSA}$, and $20 \mu \mathrm{L}$ of the solution was added into the substrates inlet (Fig. S-1A). $1 \mu \mathrm{L}$ of enzyme mix reagent from the glycerol assay kit was mixed with $99 \mu \mathrm{L}$ glycerol assay buffer with $0.25 \%$ BSA and $20 \mu \mathrm{L}$ of the solution was loaded into the enzyme inlet (Fig. S-1A). $85 \mu \mathrm{M}$ resorufin was prepared in DMEM (no glucose, no glutamine, no phenol red) with $1 \%$ BSA and added into the reference inlet. HFE-7500 with 0.5\% Pico-Surf was used as oil phase and loaded in the oil inlet (Fig. S-1A, inlet1). The glycerol standards $(0 \mu \mathrm{M}, 18.75 \mu \mathrm{M}, 37.5 \mu \mathrm{M}, 75 \mu \mathrm{M}, 150 \mu \mathrm{M}$, and $300 \mu \mathrm{M})$ were diluted from $0.1 \mathrm{M}$ glycerol stock by DMEM (no glucose, no glutamine, no phenol red) with $0.25 \% \mathrm{BSA}$, and $30 \mu \mathrm{L}$ of the solution was added into the cell culture inlet (Fig. S-1A, inlet3) sequentially. An in-house written LabVIEW program was run to form droplets, generating 1 sample droplet and 1 reference droplet (of smaller volume) every 3.48 seconds. The following timing was used throughout this work: $350 \mathrm{~ms}$ sample pumping time for 2 pump cycles, $350 \mathrm{~ms}$ oil pumping time for 3 cycles, $250 \mathrm{~ms}$ of reference pumping time for 2 cycles, and another $350 \mathrm{~ms}$ oil pumping time for 3 cycles, with several delays of 10 to $70 \mathrm{~ms}$ built into the programming [total cycle time $=(70+350) * 2+10+(350) * 3+10+(250) * 2+10+(350) * 3+10=$ $3480 \mathrm{~ms}=3.48 \mathrm{~s}]$.

For every experiment with cells or tissues, the microdevice was calibrated with glycerol standards before cell sampling. Substrate and ATP were mixed and loaded in the left reservoir (see Fig. S-1A), the enzyme mixture was added into the middle reservoir, and different concentrations of glycerol were added into the right reservoir in sequence. Each concentration of glycerol was loaded to form droplets for $\sim 8 \mathrm{~min}$, then the input (right reservoir) was changed to another concentration of glycerol by pipette. $85 \mu \mathrm{M}$ of resorufin was utilized as the reference to use our phase-locked detection concept ( $\mu$ Chopper) for correcting fluctuations of fluorescence measurements by imaging

$32,33,59$. Other than the cell/tissue culture reservoir, the reagents in the other three reservoirs were sealed by mineral oil to avoid evaporation during hours-long experiments (see Fig. S-1D). Generated droplets travelled in the long incubation channel for $\sim 8$ min to reach the plateau of enzyme reaction before the fluorescence images were taken. The BSA in the assay buffers was shown to obviate the cross-talk of resorufin ${ }^{60}$ between droplets compared to the test without BSA (data not shown). Besides, BSA is also required for cell secretion experiments, since these proteins help carry lipolysis products such as fatty acids through solution and thereby reduce auto-inhibition 
effects, and they also reduce non-specific adsorption of biomolecules to the device surfaces ${ }^{61}$. Data indicate that enzyme reactions in droplets can reach equilibrium within about $1 \mathrm{~min}$ in static droplets (Fig. S-7), and the reaction rate is faster in moving droplets due to the mixing by forming counter rotating vortices ${ }^{62}$.

Fluorescence imaging in the detection window (Fig. S-1A) was operated continuously, and images were collected at $150 \mathrm{~ms}$ intervals using the TRITC filter cube $\left(\lambda_{\mathrm{ex}}=540 / 25 \mathrm{~nm}, \lambda_{\mathrm{em}}=605 / 55 \mathrm{~nm}\right)$ by a CCD camera (CoolSnap HQ2; Photometrics Scientific) interfaced with Nikon inverted Ti-E fluorescence microscope (40X objective, $0.75 \mathrm{NA}$ ). After images were collected, the fluorescence intensity data of sample and reference droplets were obtained by image analysis in ImageJ (Fig. S-5), and the fluorescence intensity ratio between the sample droplet and reference droplet was determined continuously in response to glycerol concentration changes, shown in Fig. S-2A. In the calibration curve of glycerol (Fig. S-2B), the limit of detection was determined to be $0.74 \mu \mathrm{M}$ in the droplets, which in one droplet $(2.58 \mathrm{~nL})$ corresponds to merely $1.92 \mathrm{fmol}$ of glycerol. The average percent coefficient of variance (\%CV) of the glycerol assay in droplets was about $1.7 \%$. It can be observed that the fluctuations shown in raw data from reference droplets, due to optical perturbations during changing of glycerol solutions, could be corrected through our lock-in droplet analysis methodology ${ }^{32,33,59}$; Fig. S-2 shows the corrected data.

For the glycerol secretion sampling from eWAT and encapsulated 3T3-L1 adipocytes, the experimental settings and droplet timing were equivalent to those during calibration, except that the cell culture inlet was loaded with tissue explants or cell encapsulations. The pretreated tissue explant or agarose gel spheroids with encapsulated cells were added into the 0.75 -mm reservoir in the cell culture inlet

(Fig. S-1C, inlet3). For the eWAT explant, a 3D-printed insert was used to help trap the tissue ${ }^{18,58}$ (red 3D CAD design shown in Fig. S1B). The treatments of HGHI [ $25 \mathrm{mM}$ glucose and $2 \mathrm{nM}$ insulin in DMEM (no glucose, no glutamine, no phenol red), with $0.25 \% \mathrm{BSA}$ ] and LGLIS [ $3 \mathrm{mM}$ glucose, $50 \mathrm{pM}$ insulin with $20 \mu \mathrm{M}$ isoproterenol in DMEM (no glucose, no glutamine, no phenol red), with $0.25 \% \mathrm{BSA}$ ] were administrated to the cell culture inlet alternatively to test the glycerol secretion response from the samples. Fluorescent images were captured similarly as above. The fluorescence intensity data from the images were analyzed by Image J and data was further processed and analyzed in Microsoft Excel.

\section{9. mRNA analysis}

The RNeasy Mini Kit from Qiagen was used to extract total RNA from adipose tissue. The One-Step RT-PCR Kit from Qiagen was also purchased, and SYBR Green was added into the kit for quantitative PCR (qPCR) measurements. Beta-actin mRNA was quantified for the normalization of gene expression. The sequences of primers were from a previous publication ${ }^{43}$ (listed below) and were obtained from IDT (Coralville, IA):

Beta-actin_Forward: GACGGCCAGGTCATCACTAT 
Beta-actin_Reverse: CTTCTGCATCCTGTCAGCAA

AQ7_Forward: ATGGCCCCCAGGTCTGTGCTG

AQ7_Reverse: TTAGAAGTGCTCTAGAGGCACAGAGCC.

\section{Photobleaching for gap junction studies in mouse eWAT}

5-CFDA-AM (5-Carboxyfluorescein diacetate, acetoxymethyl ester) was dissolved in dry DMSO to obtain $5 \mathrm{mg} / \mathrm{mL}$ stock solution (9.4mM). Three different treatment solutions were prepared: Control: $10 \mu \mathrm{M}$ CFDA-AM in DPBS buffer; 2-APB treatment: $10 \mu \mathrm{M}$ CFDA-AM with $100 \mu \mathrm{M}$ 2-APB (2-aminoethoxydiphenyl borate) in DPBS buffer; 2-APB plus 6-OHDA treatment: $10 \mu \mathrm{M}$ CFDA-AM with $100 \mu \mathrm{M} 2-\mathrm{APB}$ and $1.82 \mu \mathrm{g} / \mu \mathrm{L}$ 6-OHDA in DPBS buffer. The fat explants were washed in DPBS buffer, then set in the treatment solution

for $1 \mathrm{~h}$. After treating, the tissues were rinsed by DPBS 3 times and set in the DPBS buffer for imaging. In total, 6 explants from each mouse were used, with two for each treatment, and two mice were used for the test. Images were acquired by a Nikon A1R MP Confocal Microscope using a 10X objective, with a $488.0 \mathrm{~nm}$ laser line used for photobleaching and for excitation of fluorescence in the permeabilized 5-CFDA dye. This method allowed quantification of small molecule transfer rates between cells in the eWAT.

\section{Immunostaining of mouse eWAT}

Every piece of 3-mm WAT was washed by DPBS buffer and fixed in $200 \mu \mathrm{L}$ Image-IT Fixative solution (4\% formaldehyde in PBS, methanol-free) at $4{ }^{\circ} \mathrm{C}$ overnight. The tissues were washed by incubating in $200 \mu \mathrm{L} \mathrm{DPBS}$ at $4{ }^{\circ} \mathrm{C}$ for $2 \mathrm{~h}$, then treated by $20 \mu \mathrm{g} / \mathrm{mL}$ proteinase $\mathrm{K}$ in $10 \mathrm{mM}$ Tris- $\mathrm{HCl}$ for $5 \mathrm{~min}$ at room temperature. This was followed by incubating in $100 \%$ methanol at $-20^{\circ} \mathrm{C}$ for $5 \mathrm{~min}$ and PBS buffer with $1 \%$ BSA and $0.3 \%$ Triton X-100 at $37^{\circ} \mathrm{C}$ overnight to permeabilize the tissues and block the non-specific binding. The tissues were incubated with antibody solutions at $37^{\circ} \mathrm{C}$ for $5 \mathrm{~h}$ and $4{ }^{\circ} \mathrm{C}$ overnight. Either 1:250 diluted Connexin 43 monoclonal antibody (CX-1B1) labeled by Alexa Fluor $488(0.5 \mathrm{mg} / \mathrm{mL}$ in stock solution), or 1:100 diluted TH antibody (F-11) Alexa Fluor 594 (0.2 mg/mL in stock solution) were used. The tissues were then washed by DPBS and incubated in $3 \mu \mathrm{g} / \mathrm{mL}$ Nile red $(1 \mathrm{mg} / \mathrm{mL}$ in stock solution) or 1:1000 diluted LipidTox Green at $37^{\circ} \mathrm{C}$ for $5 \mathrm{~min}$ to stain the lipid droplets in the adipocytes. The tissues were finally washed by DPBS, then set in DPBS and anchored at the bottom of culture plate using 3D-printed insert for imaging. Immunostained cell images were captured by the Nikon A1R MP Confocal Microscope using a 10X objective.

\section{Spectrogram generation}

Time traces of glycerol secretion, e.g. from Fig. 2, were first processed with a 57-point (198.36-second or 3.306-minute) moving average filter in Excel, which is essentially a high-pass filter with a cutoff frequency of $0.151 \mathrm{~min}^{-1}$ that removed the slow changes (baseline) and left the higher frequency bursts. Next, an in-house written LabVIEW application applied a 128-point (7.42-min), sliding window FFT analysis 
with a uniform windowing method, creating an image file with time on the $x$-axis and frequency on the $y$-axis. These images were further processed in ImageJ to give a logarithmic intensity scale using a 16-color lookup table, as shown in Fig. 3 and Fig. 6. 


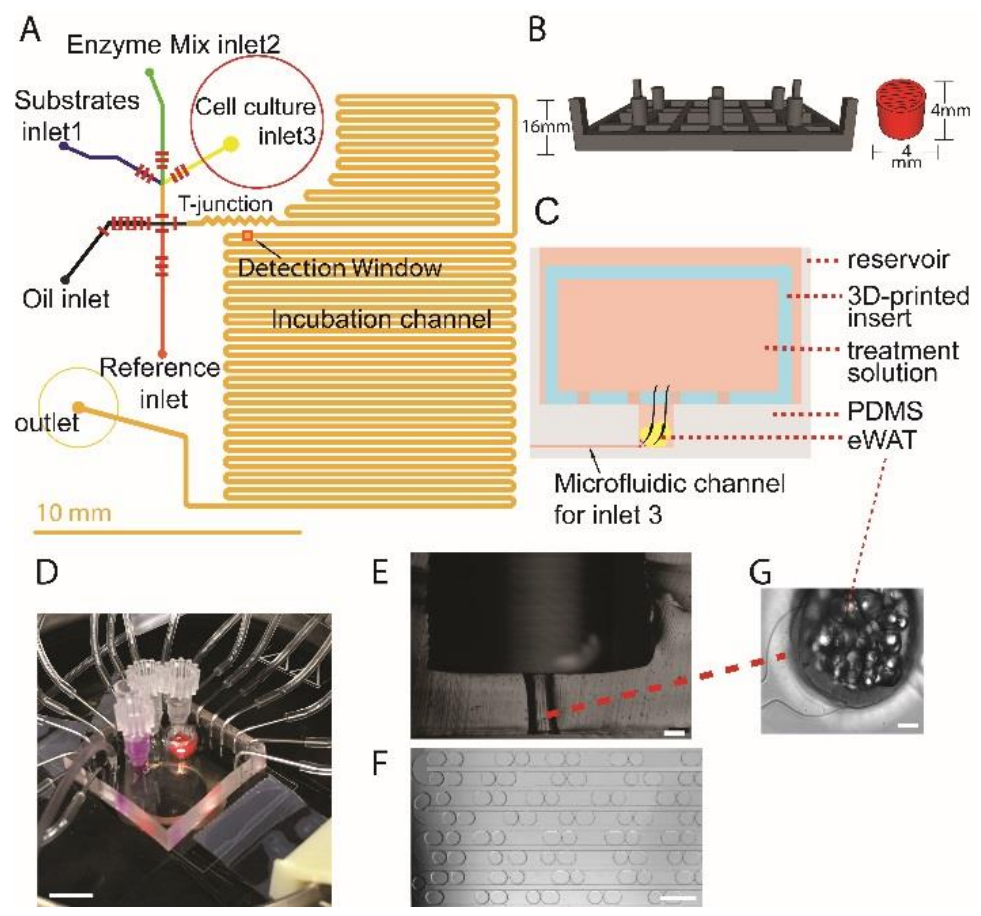

Figure S-1. Microchip design and experimental setup. A) The two-layer microfluidic chip design: the short red lines, representing the microvalves, were in the bottom layer for pneumatic control; the inlets, flow channels (black), and incubation channel (orange) were in the top layer for fluid flow. B) 3D-printed template (dark gray) for cell culture reservoir fabrication, and the 3D-printed insert (red) used in eWAT tissue sampling to trap the tissue in the reservoir during solution exchange. C) Schematic figure of the cross-section of cell/tissueculture reservoir. D) Photograph of the experimental setup on the stage of a fluorescence microscope, connected to solenoid switches. Scale bar $=1 \mathrm{~cm}$. E) Sliced cross section of cell/tissue reservoir. The upper open reservoir was for bulk solution, and the narrow lower part was for trapping tissue or cell spheroids close to microchannel. Scale bar $=500 \mu \mathrm{m}$. F) Formed droplets containing digitized secretome as they flowed through the long-incubation channel, with small-sized droplets as references and large sample droplets (see supplementary video 1). Scale bar $=500 \mu \mathrm{m} . \mathrm{G})$ Example eWAT tissue image in the narrow part of the reservoir in E, connected to the microchannel for sample droplet formation. Scale bar $=150 \mu \mathrm{m}$. 

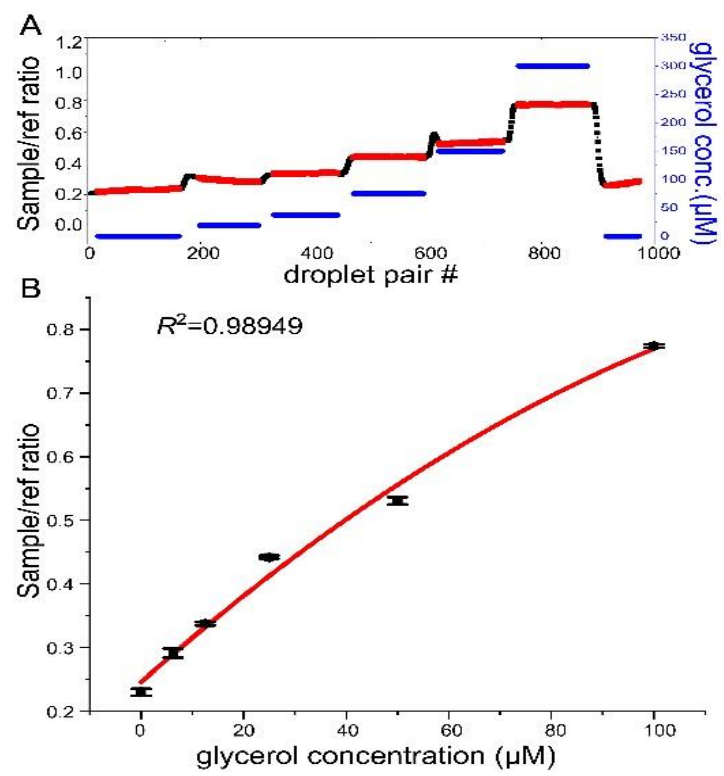

Figure S-2. Example calibration of the fluorescent enzyme assay specific for glycerol in droplets. A) The sample-to-reference ratio (from raw data in Fig. S-5) for each droplet pair responded quantitatively to the different concentrations of glycerol loaded into the cell culture inlet. Red labeled data were used in the standard curve calculation. B) Corresponding calibration curve, which was fitted to a quadratic polynomial model, where $R^{2}=0.98949$. A similar calibration was carried out at least once per day during the cell or tissue sampling expeirments. 


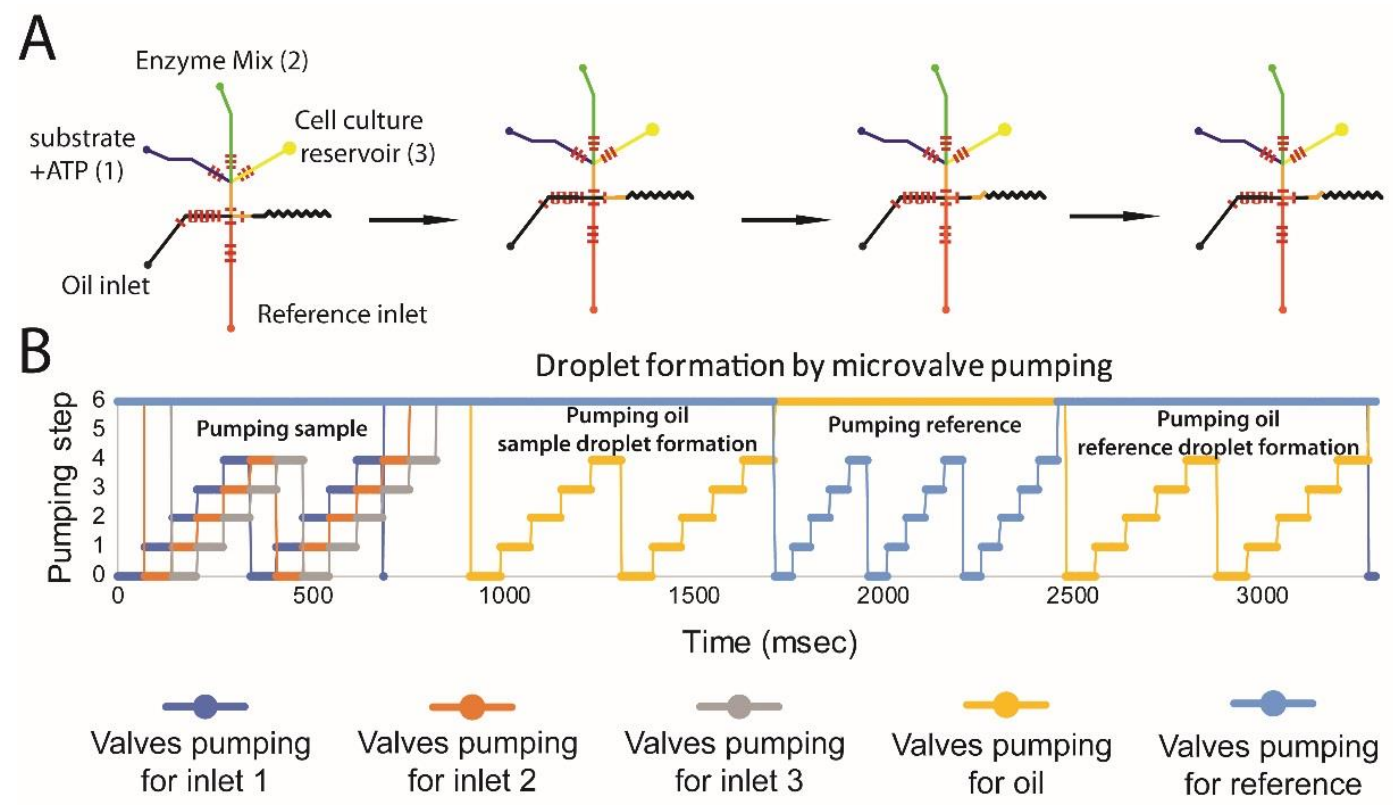

Figure S-3. In-house written LabVIEW application was run to control the formation of continuous pairs of sample and reference droplets.

A) Schematic figure shows the open/closed states of microvalves in control layer for droplet formation. B) 5-step pumping was used to control the solution flowing into the channel sequentially to generate a pair of droplets. Each micropump included three valves, and the pumping steps for each group of microvalves are labelled from 0 to 4 , representing the $001,101,100,110,111,(1=$ closed and $0=$ open; 5 is 000 and 6 means 111).
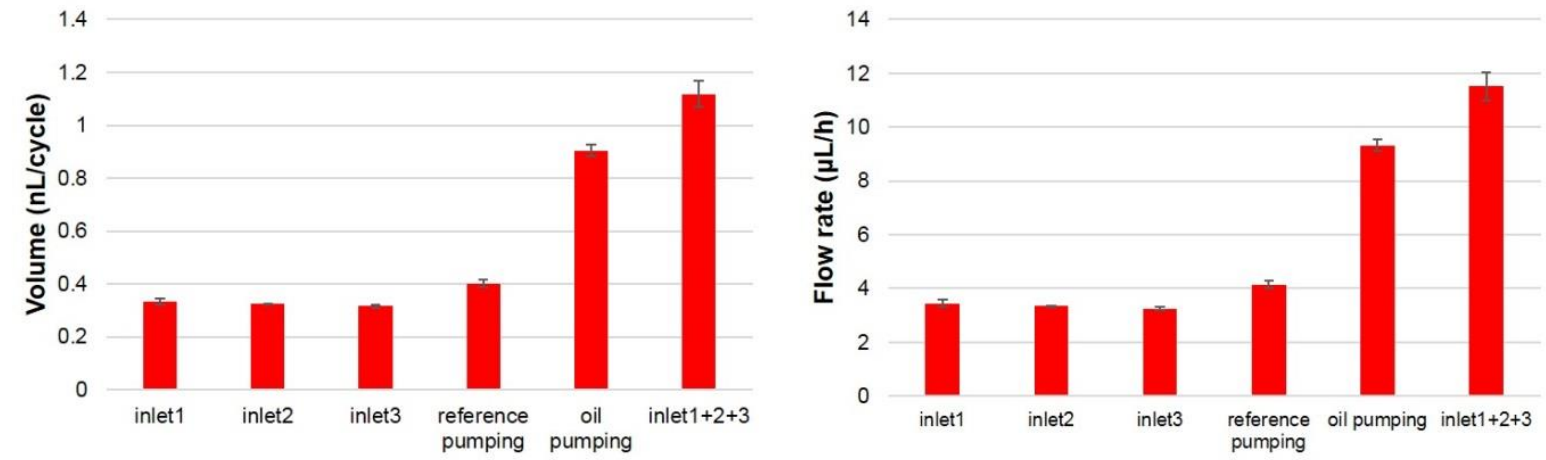

Figure S-4. Measurement of the valve pumping volumes. A) Volume for each pumping cycle from the various inlets; 3 tests were done for each group of valves, with timing as described in SI, section 8. B) Flow rate measurement by pumping each group of valves. 


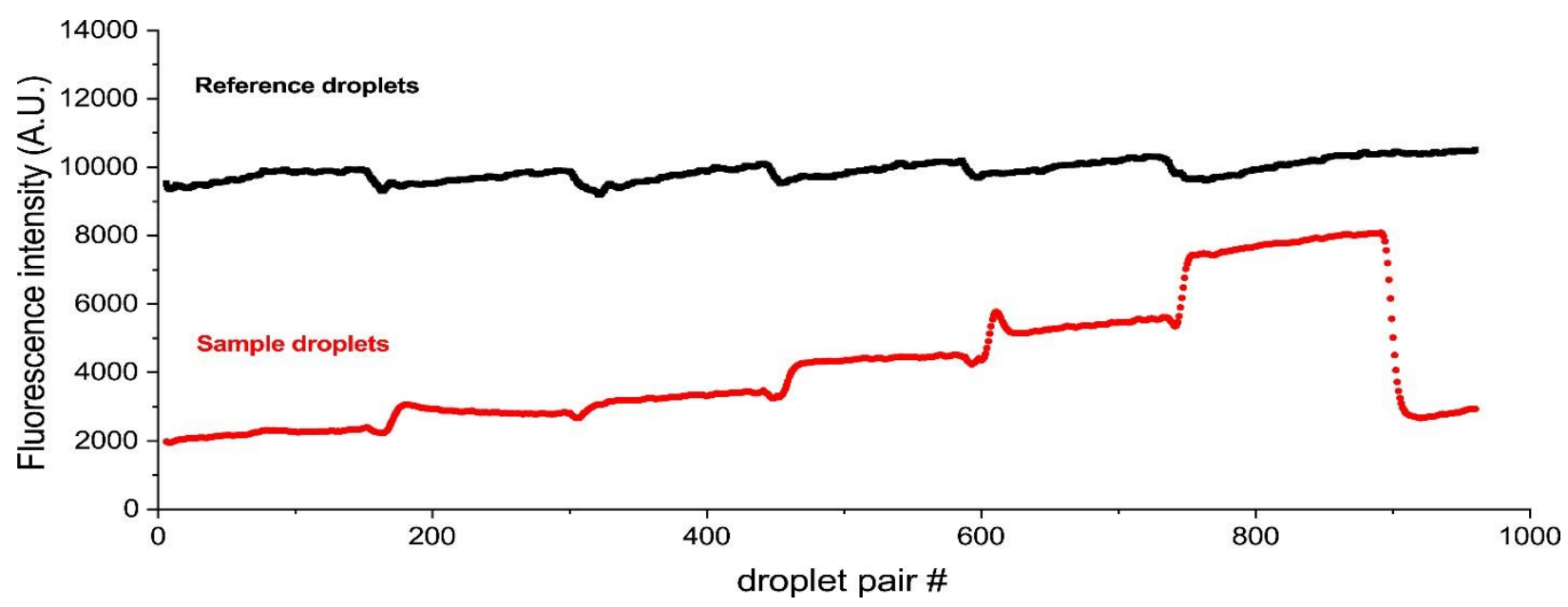

Figure S-5. Raw data of fluorescence intensity for each droplet during continuous, on-chip calibration. The fluorescence images were analyzed by ImageJ. Based on the droplet size and sequence, reference droplets could be separated from the sample droplets. The number of each droplet pair is shown on the $\mathrm{x}$-axis, corresponding to about 55 minutes total for $\sim 1000$ droplets.

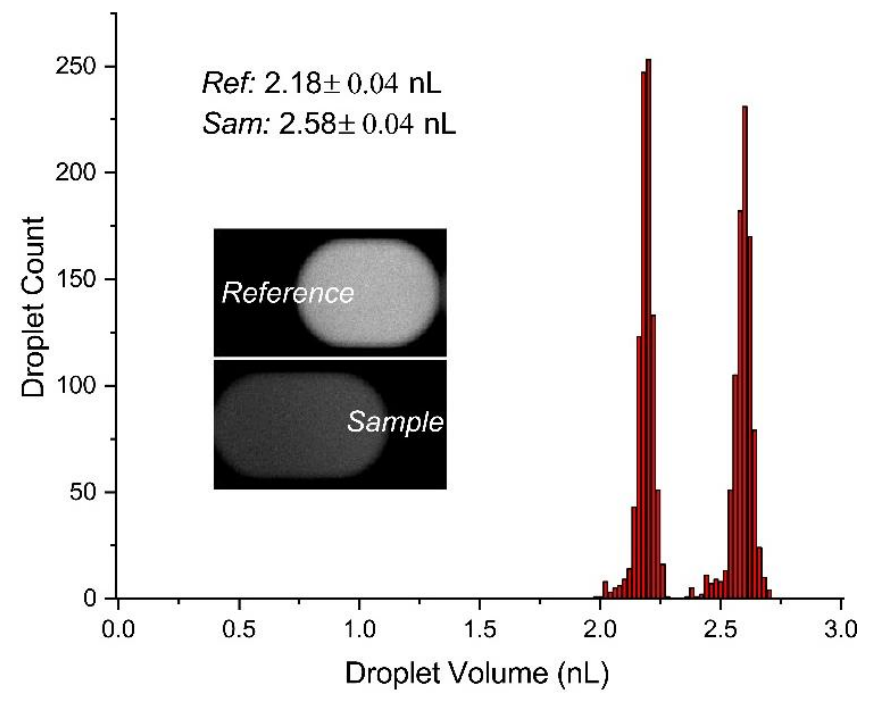

Figure S-6. Droplet volume measurement shows high precision control with our device, using 914 droplets of each type. The volumes of droplets were calculated by $=A \cdot h+\frac{\pi \cdot h^{2} \cdot P}{8}$, where $h$ is the channel depth, $A$ is the droplet area from top view images, and $P$ is the perimeter of the droplet. 


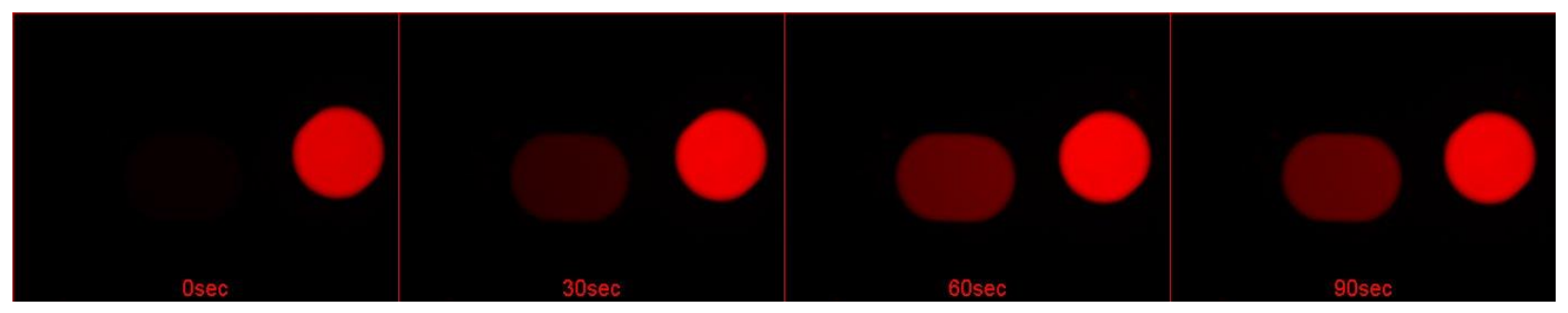

Figure S-7. To confirm efficient droplet-based enzyme reaction efficiency in early tests, the progress of the detection kit's enzyme reaction was monitored in static droplets. The smaller droplet was the reference droplet with $85 \mu \mathrm{M}$ resorufin, and the larger droplet was the sample droplet containing $100 \mu \mathrm{M}$ glycerol, enzymes, substrate, and ATP. Imaging started as soon as the droplets were formed. The produced fluorogenic molecule, resorufin, in the static sample droplet reached its highest concentration within about one minute.

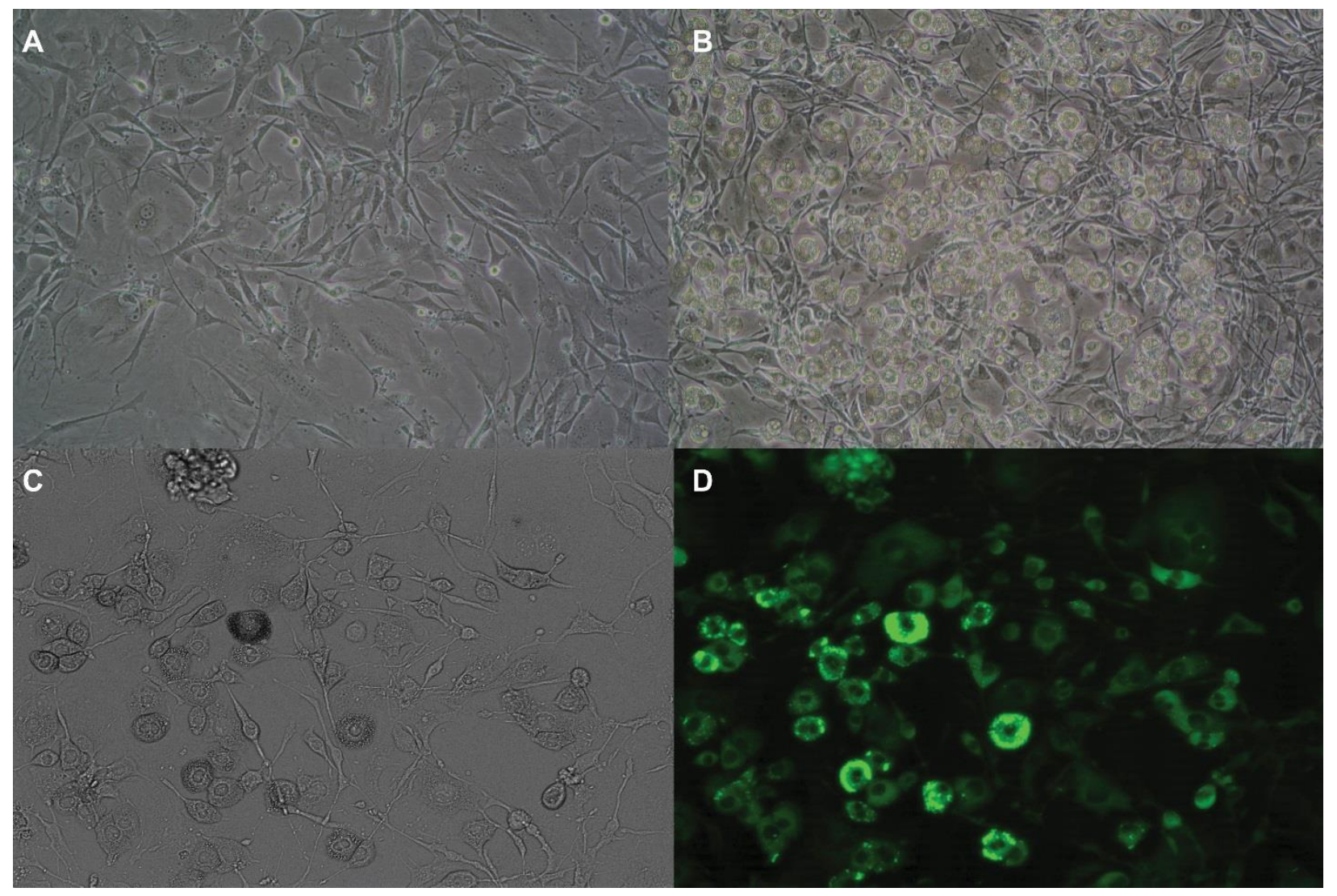

Figure S-8. Culture and differentiation of the 3T3-L1 cell line. A) Fibroblasts of 3T3-L1 at around 90\% confluence. B) Differentiated 3T3-L1 adipocytes. The cell morphology was changed from fibroblast-like to circular shaped with visible lipid droplets formed in the cells. A and B were captured by a digital camera (Nikon J1) under 10X magnification. C) DIC image and D) corresponding fluorescence image of 3T3-L1 adipocytes by the objective with 10X magnification (Nikon Ti-E). The lipid droplets in the adipocytes were stained by LipidTox Green and detected in the FITC channel of the fluorescence microscope. 


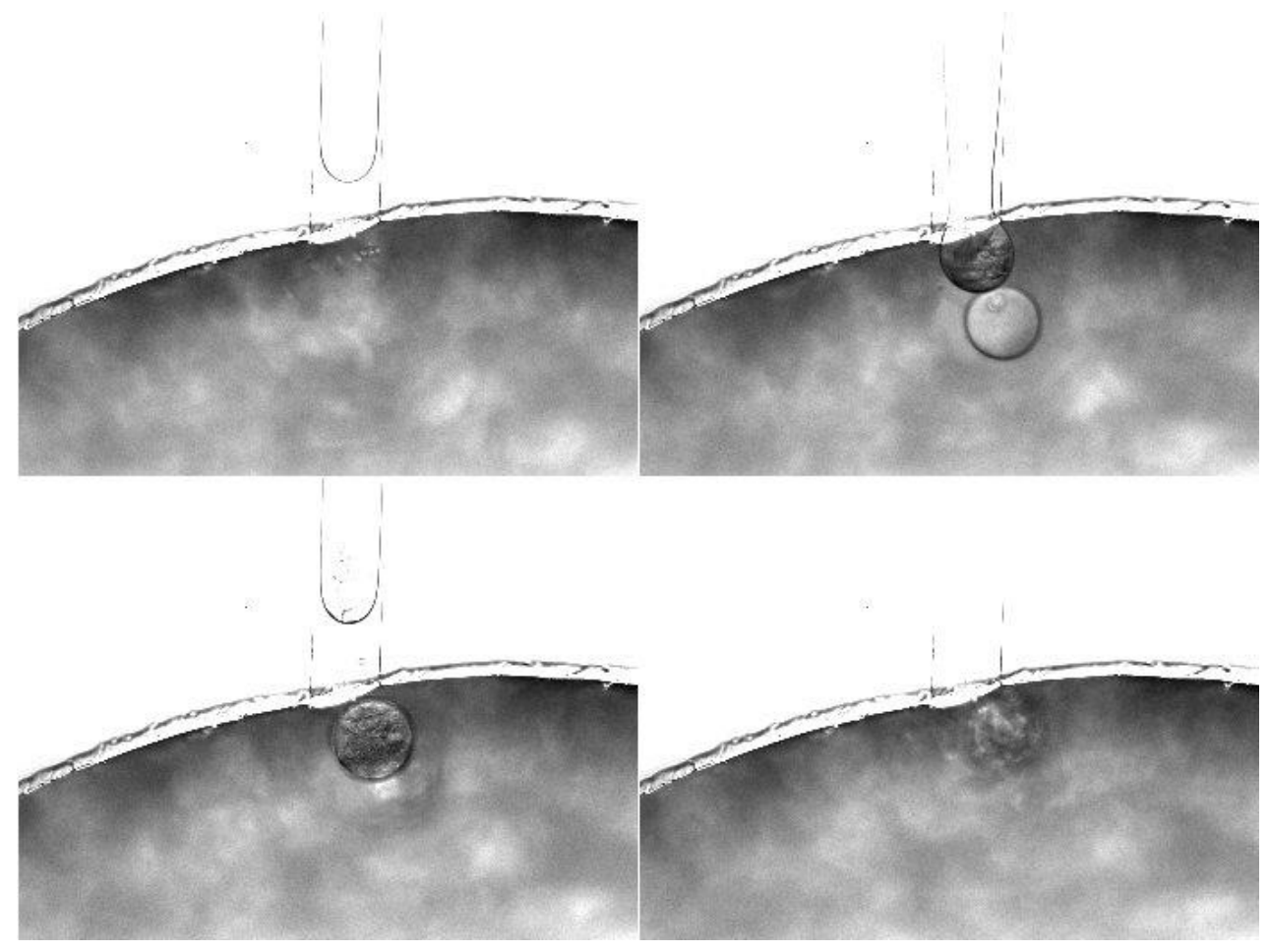

Figure S-9. Cell spheroid generation using 3T3-L1 adipocytes and agarose in the microfluidic droplet chip (see also supplementary video 2). Cells encapsulated in droplets of liquid agarose gel are shown as they exit the microfluidic channel (top) and enter the reservoir (bottom). 

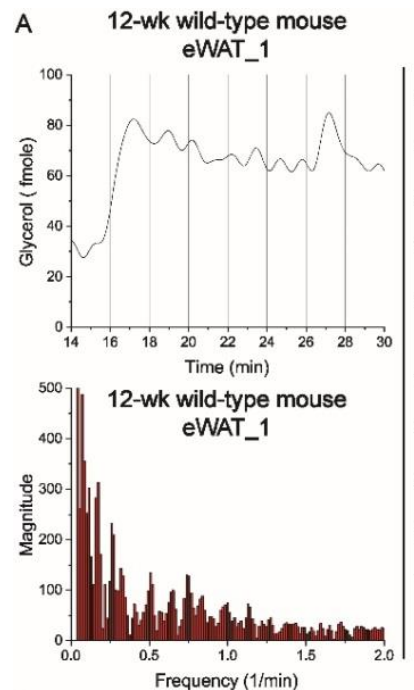

D
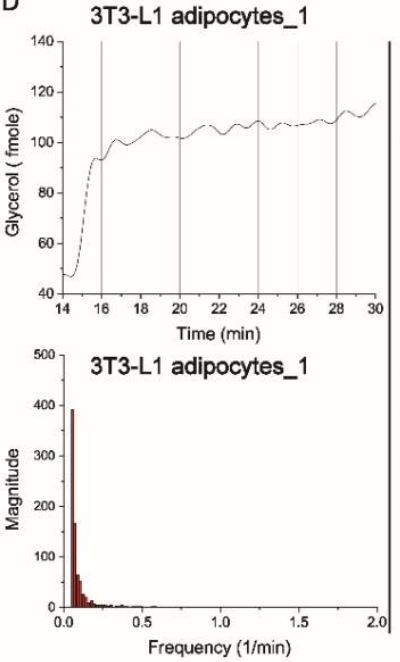

$I_{500}$

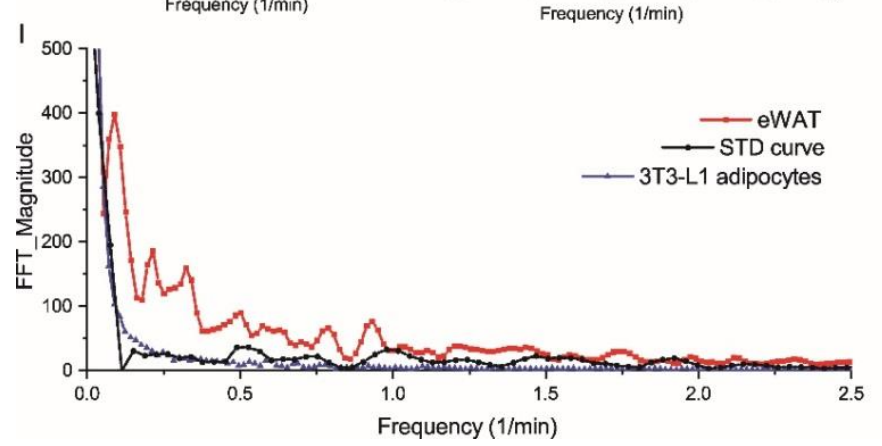

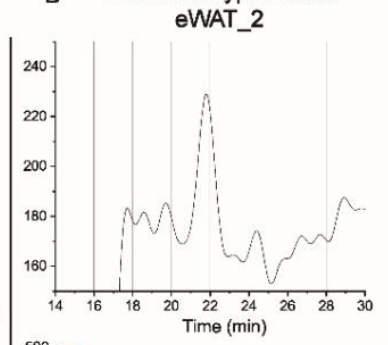

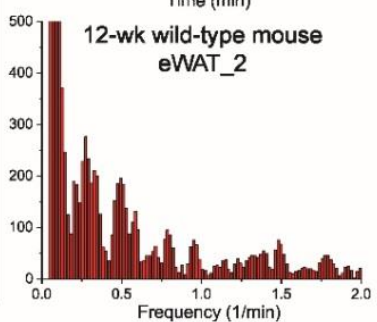

E 3T3-L1 adipocytes_2
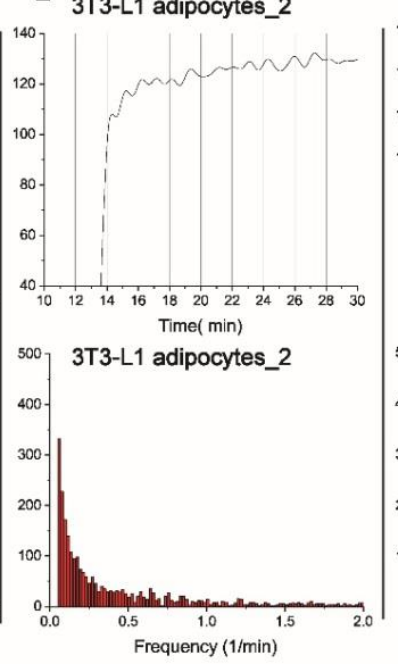

C 12-wk wild-type mouse eWAT_3
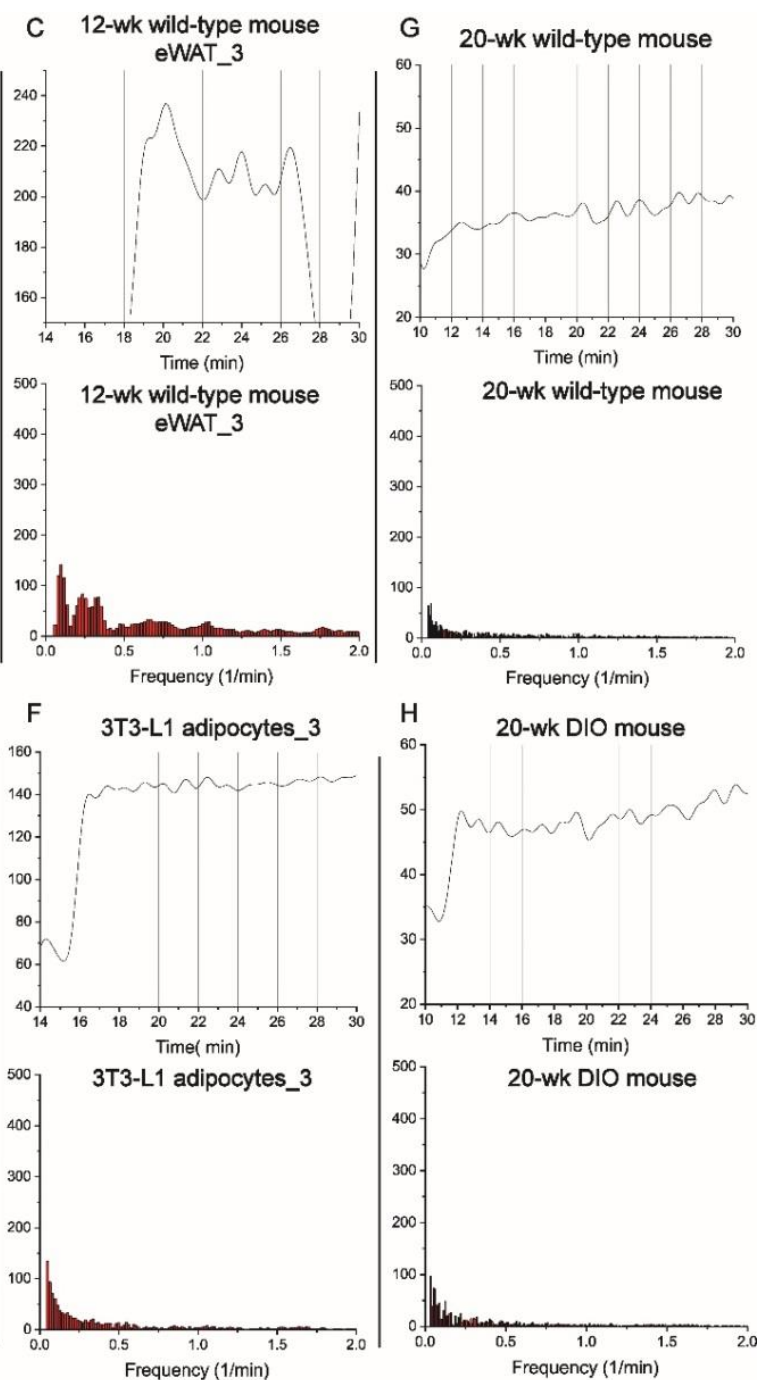

Figure S-10. A-H) Oscillation analyses of glycerol release from primary white adipose tissues and 3T3-L1 adipocytes. For each group of data from Fig. 2, the upper figure shows part of the plot after analyzed by low-pass filter with $1.0 \mathrm{~min}^{-1}$ frequency cutoff. The lower plot displays the FFT results. Overall, we observed fewer oscillations/bursts from 3T3-L1 adipocytes and eWAT of old mice than from eWAT of 12-week wild-type mice. I) Average magnitude in FFT analysis to show the difference between the tissues and cell clusters, proven by comparing with the FFT analysis of standard curve $(n=3)$. 


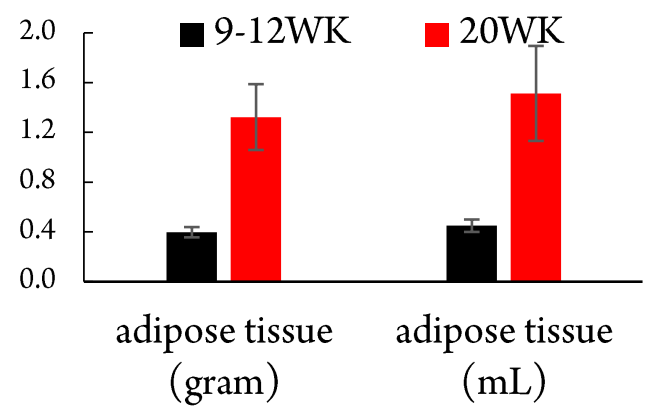

Figure S-11. Adipose tissue mass and volume for 9-12-week old mice and 20-week old mice. Data included three mice for each age group. Note that DIO mice eWAT weight was 2.30 grams.

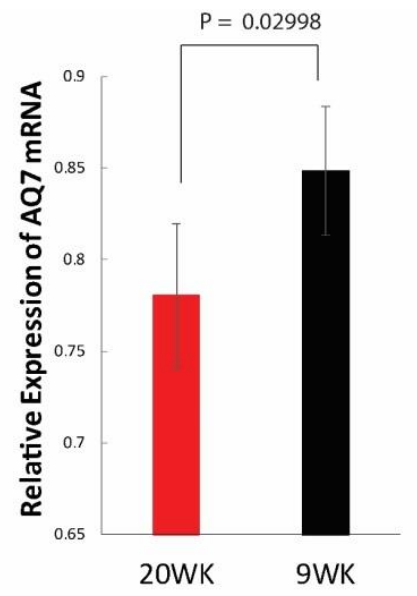

Figure S-12. Aquaporin 7 gene expression in mice of different ages, normalized to that of beta-actin expression. Data included three or more samples from each mouse. 